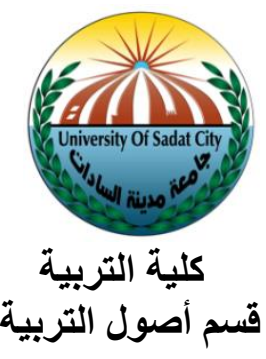

"دور الإدارة المدرسية في زيادة الفاعلية التعليمية بمدارس التعليم

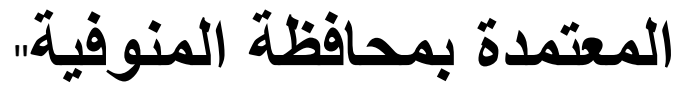

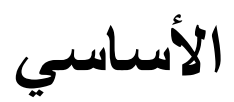

$$
\text { (دراسة ميد(نية) }
$$

" The Role of the School Administration In Increasing the Educational Effectiveness in the Accredited Basic Education Schools in Menoufia Governorate "

(Field Study)

$$
\begin{aligned}
& \text { رسالة مقدمة استكمالاً لمتطلبات الحصول على درجة الماجستير في التربية } \\
& \text { (تخصص التربية المقارنة والإدارة التعليمية ) }
\end{aligned}
$$

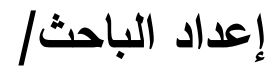

$$
\begin{aligned}
& \text { أيمن صابر القطب المراكبي }
\end{aligned}
$$

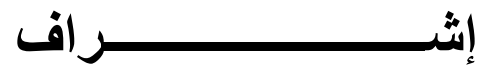

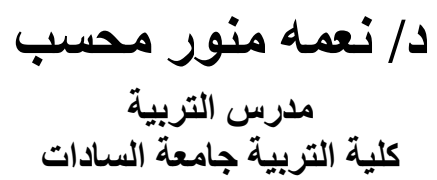

$(r \cdot 19 / 1 \leq \varepsilon \cdot)$ 


\section{مستخلص الدراسة}

هدفت هذه الدراسة إلى التعرف على دور الإدارة المدرسية في زيادة الفاعلية التعليمية بدارس التعليم الأساسي المعتمدة بمحافظة المنوفية، واستخدم الباحث المنهج الوصفي، واستخدم الاستبانة كأداة للدراسة، وقداند

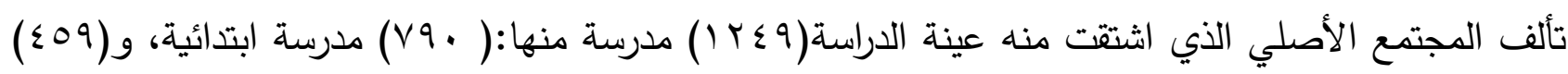

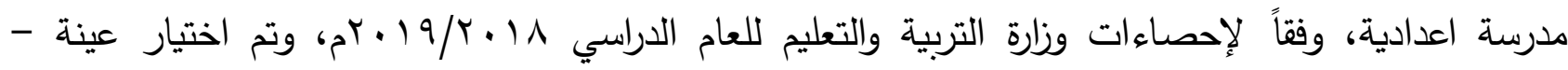

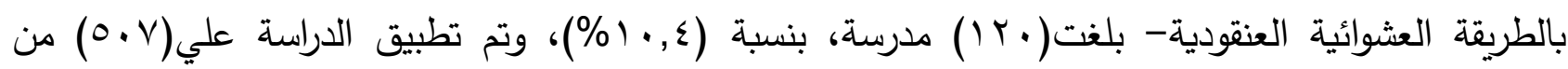

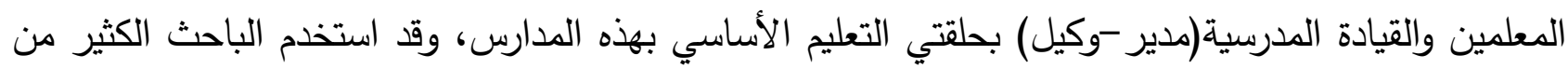

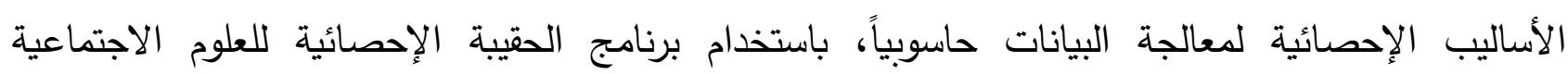
(SPSS)

وجود درجة كبيرة للفجوة والأهمية في جميع محاور وظائف الإدارة المدرسية حسب جميع متغيرات الدراسة خاصة في محوري التخطيط وصنع القرار. وجود درجة ضعيفة للممارسة في جميع محاور وظائف الإدارة الددرسية حسب جميع متغيرات الدراسة

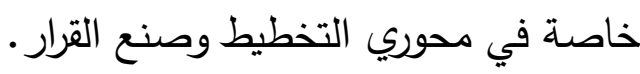
وجود درجة كبيرة للفجوة والأهمية في جميع محاور الفاعلية التعليمية بمدارس التعليم الأساسي المعتمدة بمحافظة المنوفية خاصة في محوري المعلم والمناخ التربوي. وجود درجة ضعيفة للممارسة في جميع محاور الفاعلية التعليمية بمدارس التعليم الأساسي المعتمدة بمحافظة المنوفية خاصة في محوري المتعلم والمعلم. وفى ضوء نتائج الدراسة قدم الباحث تصوراً مقترحا لزيادة الفاعلية التعليمية في مدارس التعليم الأساسي المعتمدة بمحافظة المنوفية تضمن: منطلقات، ومكونات، وإجراءات. 


\section{$\underline{\text { Abstract }}$}

Title of the study: " The Role of the School Administration In Increasing the Educational Effectiveness in the Accredited Basic Education Schools in Menoufia Governorate - Field Study"

This study aimed to identify the role of school administration in increasing the educational effectiveness in the basic education schools accredited in Menoufia governorate. The researcher used the descriptive method and used the questionnaire as a study tool. According to the statistics of the Ministry of Education for the academic year 2018/2019, (459) preparatory schools were selected, a random sample of (120) schools, representing (10.4\%), was applied to 507 teachers and school leaders. (Principal-Agent) in the two basic education workshops in these schools The researcher used a lot of statistical methods to process data computationally, using SPSS program, the study reached the most important results;

- The existence of a large degree of gap and importance in all axes of the functions of school administration according to all the variables of the study, especially in the axes of planning and decision-making.

- The presence of a weak degree of practice in all axes of school administration functions according to all variables of the study, especially in the planning and decision-making.

- The existence of a large degree of gap and importance in all axes of educational effectiveness in the schools of basic education in the governorate of Menoufia, especially in the axes of the teacher and the educational climate.

- The presence of a weak degree of practice in all axes of educational effectiveness in the schools of basic education in the governorate of Menoufia, especially in the learner and teacher.

In the light of the results of the study, the researcher presented a proposed concept to increase the educational effectiveness in the accredited basic education schools in Menoufia governorate to include: starting points, components and procedures. 


\section{الفصل الأول \\ الإطار العام للارساسة الاولة}

\section{مقدمة}

(1) تسعى المنظمات في الوقت الراهن إلى التكيف مع العوامل والمتغيرات العالمية والمحلية المعقدة والمتثابكة،

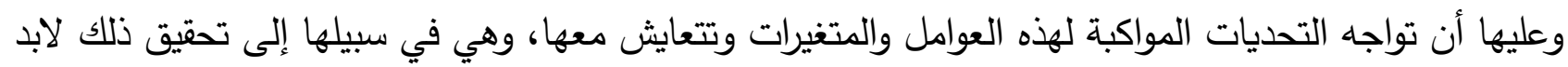

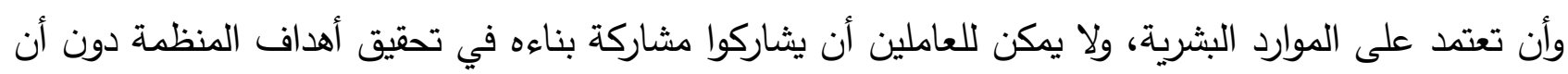

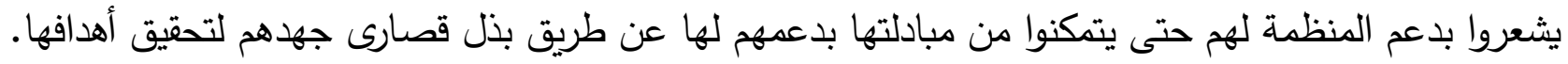

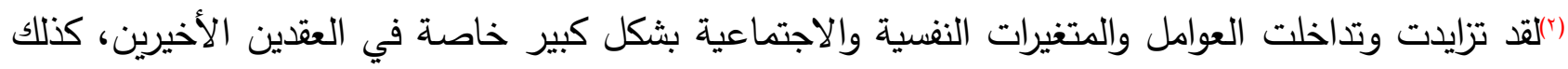
تثابكت علاقة تلك العوامل والمتغيرات فيما بينها داخليا وإن كانت تهدف جميعا إلى تتمية وتطوير الأداء

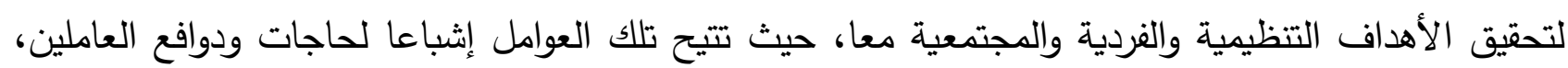

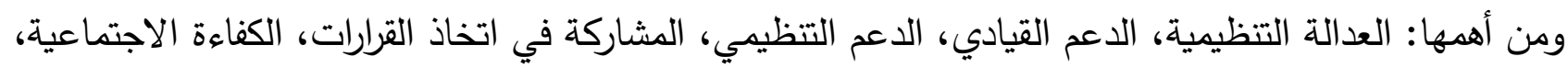

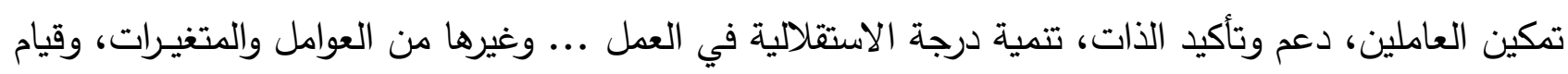

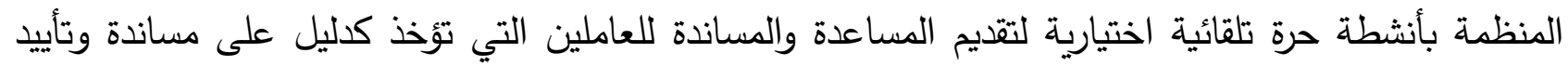
المنظمة واهتمامها بموظفيها.

(†)ويتميز عصرنا الحاضر بالسرعة الهائلة في التقدم العلمي والتكنولوجي بشكل لم يسبق له مثيل، ومن جهة أخرى فهو يواجه العديد من التحديات والمتطلبات التي تفرضها عليه طبيعته، والتي من أبرزها الانفجار السكاني، والانفجار المعرفي، ذلك بالإضافة إلى بروز العديد من المشكلات الاجتماعية والاقتصادية في

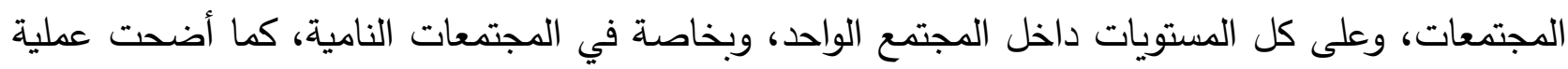

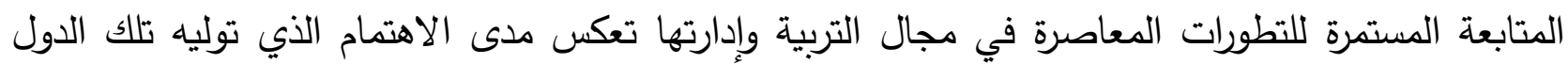

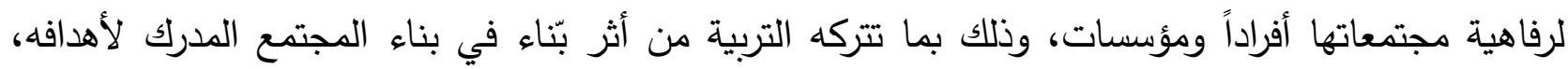

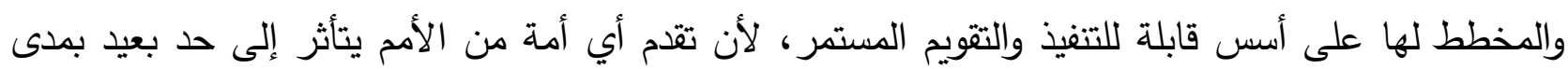

${ }^{(1)}$ Shore , L.M. \& Wayne , S.J. (1993): Commitment and employee behavior : comparison of affective commitment and continuance commitment with perceived organizational support" , journal of Applied psychology, Vol.78, pp. $774-780$.

${ }^{(2)}$ Mormon R.H. et al(2001): Does perceived organizational support mediate the relationship between procedural justice and organizational citizenship behavior?" Academy of management journal , Vol.44, pp351-357.

(ץ) فائق حسني المغربي، عربي حمودة أبو حليمة(990 (1). اتجاهات مديري المدارس في محافظة الزرقاء نحو درس التربية الرياضية من وجهة

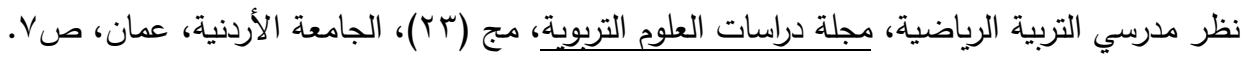


التطور العلمي والتكنولوجي الذي تحرز تلك الأمة، وإن هذا التطور الذي تصل إليه يعكس هو الآخر مدى كفاءة وفعالية أنظمتها التربوية، وسياستها التعليمية.

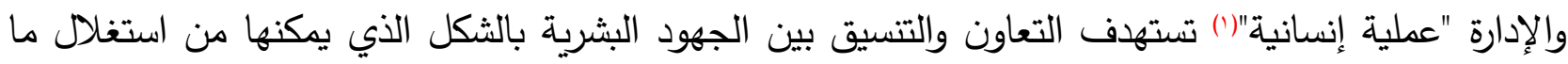

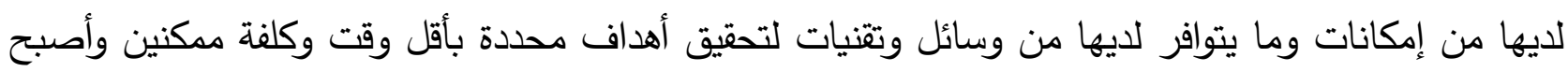

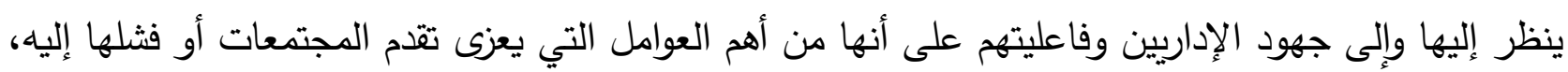

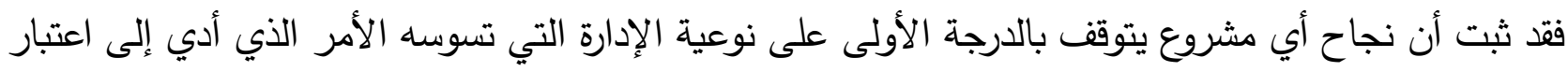

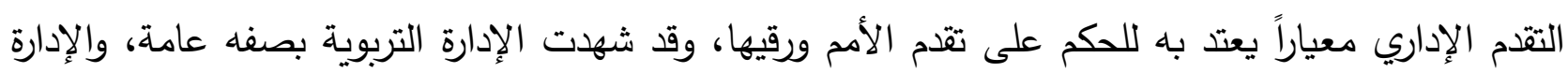

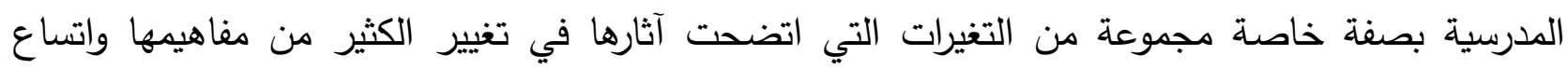
مجالات العمل فيها، والذي تغير دور مدير المدرسة في ضوئها من مجرد القيام بالواجبات الإدارية الروتينية

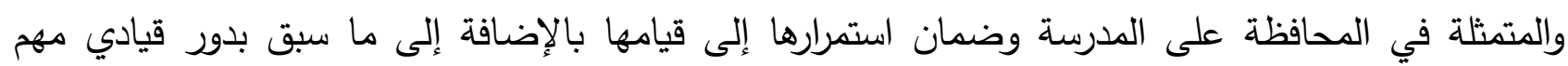
يتجسد في تغيير وتطوير البرامج والأساليب والأنشطة المدرسية.

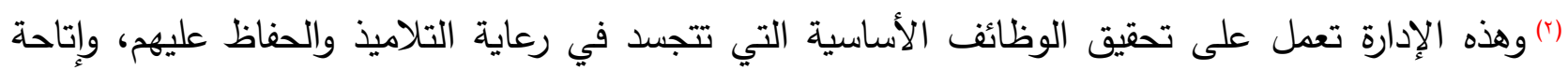

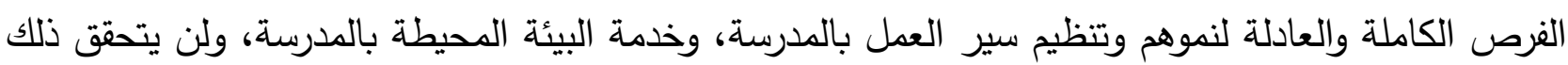
إلا عن طريق وضوح أهداف المدرسة، في أذهان جميع العاملين فيها ويعتبر هذا من أهم الضمانات الأساسية

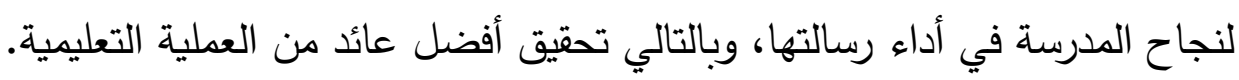

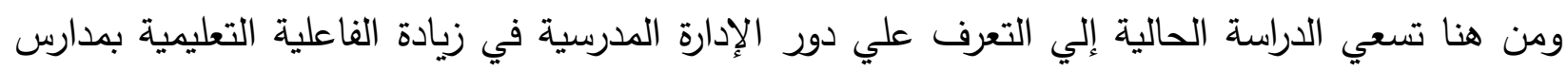

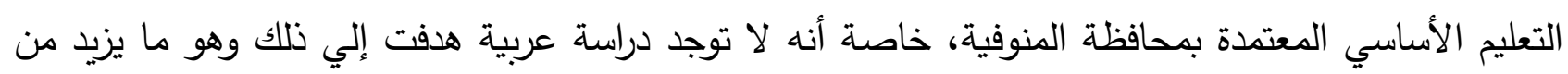
أهمية هذه الدراسة.

\section{مشكلة الدراسية وتساؤلاتها:}

يثير الأدب التزبوي والدراسات العديدة ذات العلاقة بأهمية دور الإدارة المدرسية في زيادة الفاعلية التعليمية،

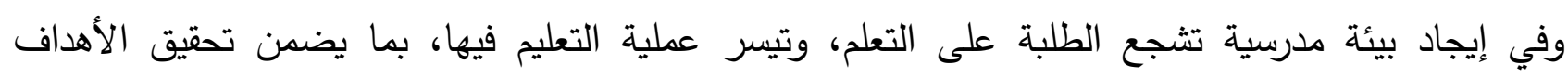

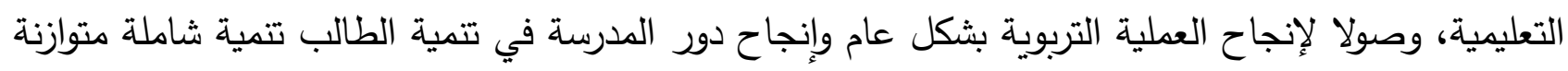

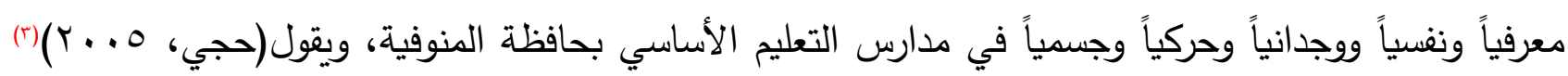

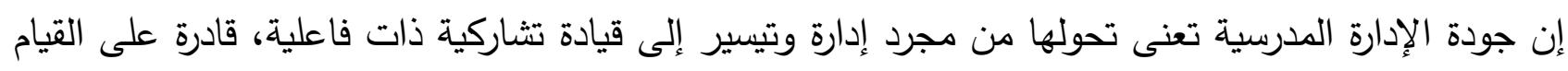

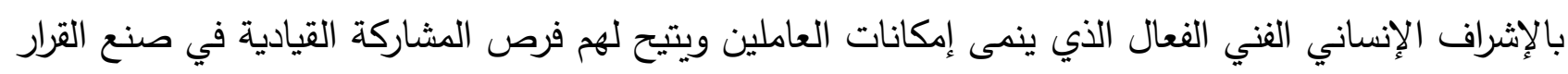

(1) أحمد الرفاعي بهجت(ب99 (1). فاعلية دورة الإدارة المدرسية في إعداد مديري الددارس بسلطنة عمان، دراسات تربوية، مج ^، ج \&ه،

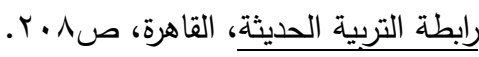

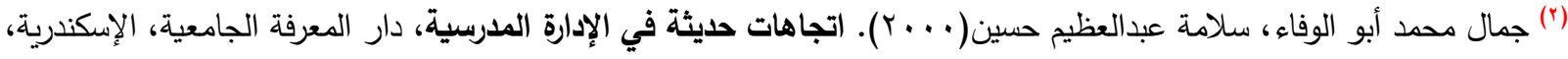

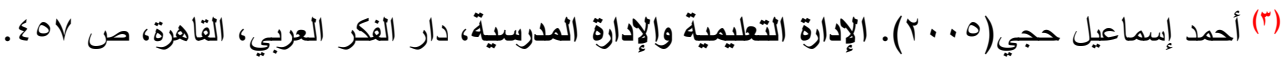


واتخاذه ورسم السياسات وتبنيها وتنفيذه ومتابعتها وتقويمها، كما أن هذه الإدارة تعمل على أساس الفريق ولا تختزل نفسها في شخص المدير فقط، ولكن العمل الجماعي الديمقراطي يمثل فلسفتها ومطلقها.

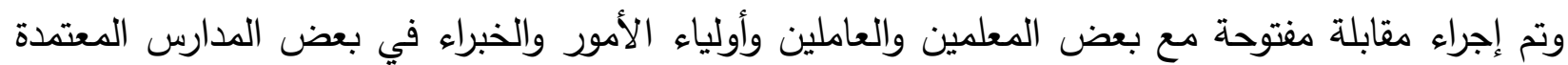

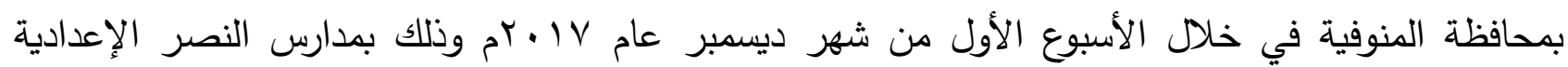

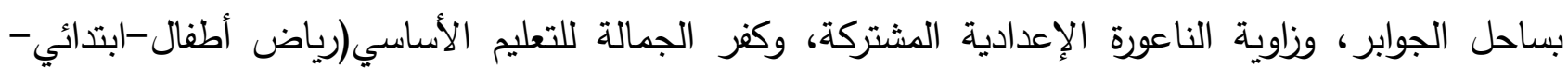

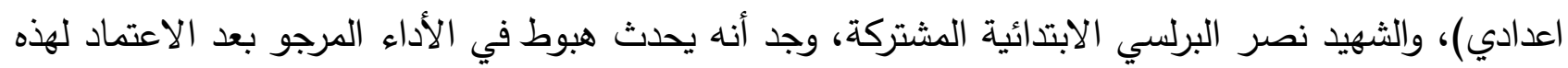

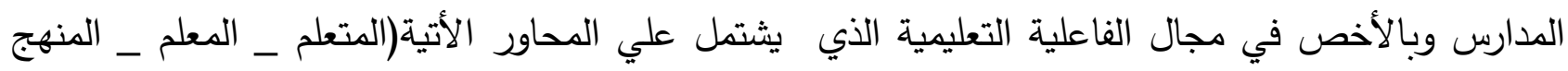
الدراسي _ المناخ التربوي )، مما يؤدي انتهاء فترة الاعتماد لبعض الددارس، أو تراجع توافر معايير الاعتماد

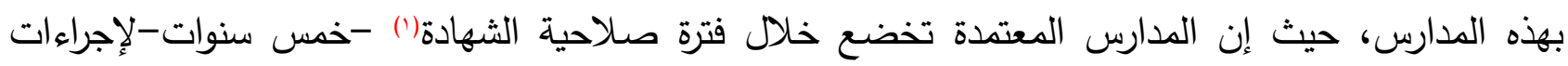

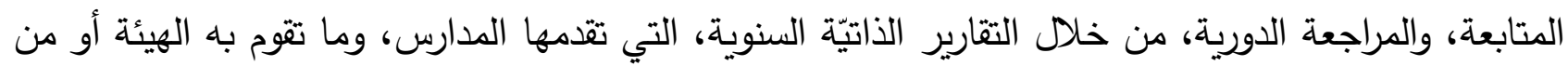
ترخص له من زيارات، للتأكد من استمرارية مقومات الاعتماد، وتخطر المؤسسة بالفترة الزمنية، التي يتم خلالها

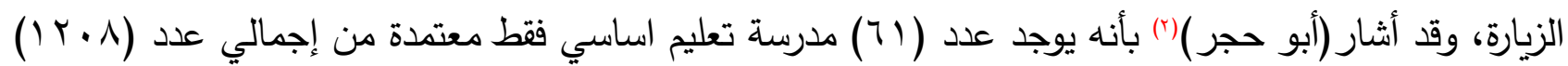

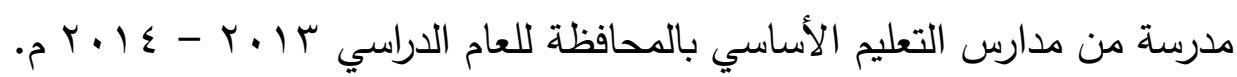
وبمقابلة فريق الجودة بالمديرية بمقر إدارة الجودة بمديرية التربية والتعليم بالمنوفية - الدور الثالث الثالثيا أفادوا بأنه

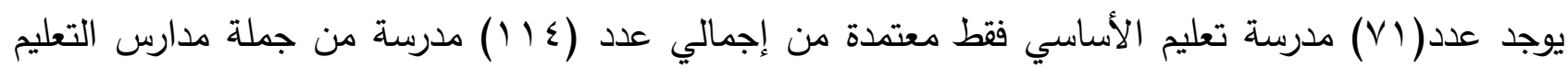

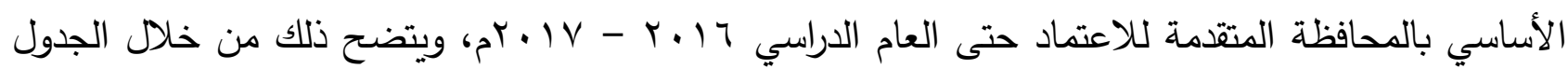
رقم (1) التالي الذي يوضح موقف مدارس التعليم الأساسي من الاعتماد بمحافظة المنوفية:

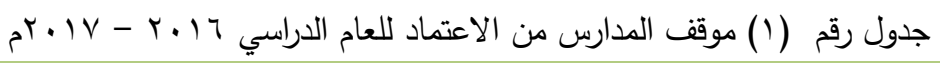

\begin{tabular}{|c|c|c|c|c|c|c|c|}
\hline النسبة & ارجاء & النسبة & انتهاء & النسبة & اعتماد & المتقدمة للاعتماد المدارس & المرحلة \\
\hline$\% \varepsilon$ & $r$ & $\%$ \% & $r l$ & $\%$ vv & 04 & $\wedge$. & ابتدائي \\
\hline$\% 9$ & $r$ & $\%$ \% v & 14 & $\%$ \% & 10 & & إعدادي \\
\hline$\%$ & 9 & \%rr & $r v$ & \% & $v_{1}$ & $11 \varepsilon$ & الجملة \\
\hline
\end{tabular}

الجدول السابق رقم (1) يوضح عدد المدارس المتقدمة للاعتماد بمحافظة المنوفية حيث أن إجمالي عدد

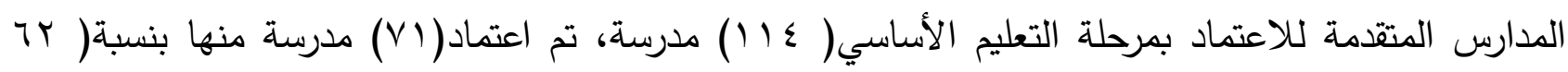

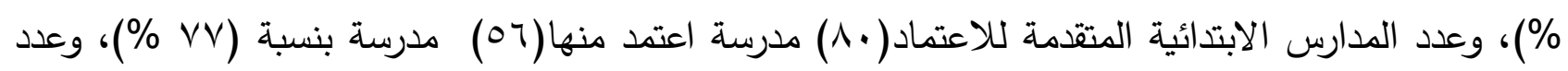

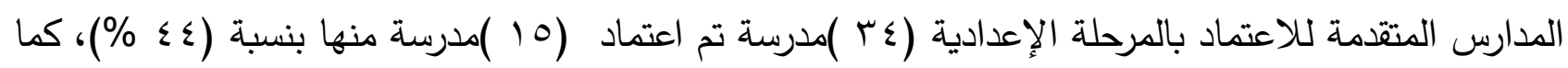

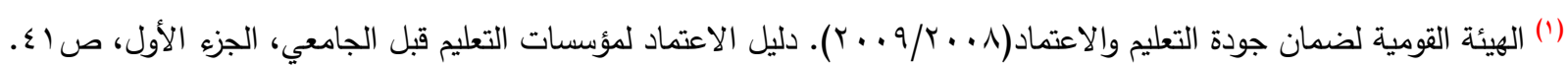

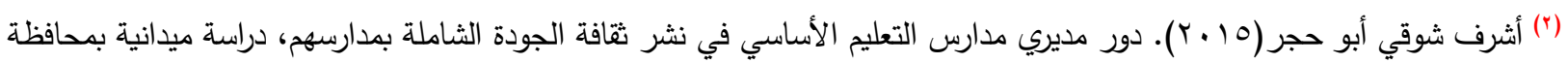

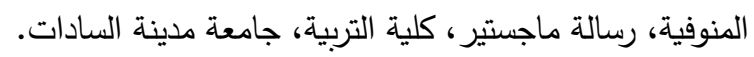


تم إرجاء اعتماد عدد(7 ) مدارس بمرحل التعليم الأساسي بنسبة(ه\%)، منها عدد( r ) مدارس بالمرحلة

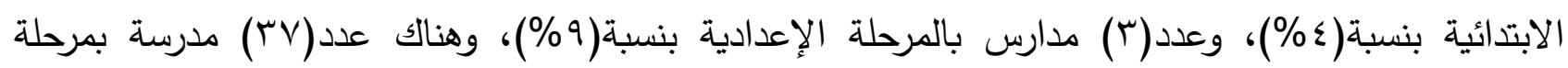

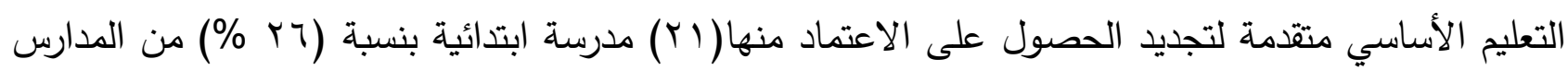

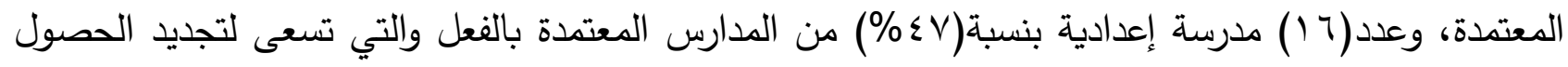
على الاعتماد.

ومن خلال عمل الباحث في الحقل التربوي، وفي مجال جودة التعليم قبل الجامعي، وكذلك من خلال استطلاع

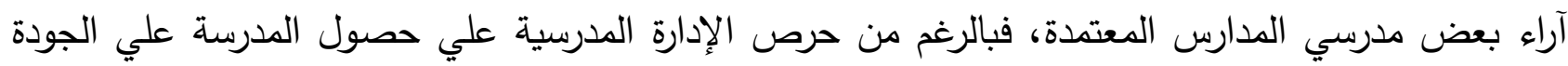

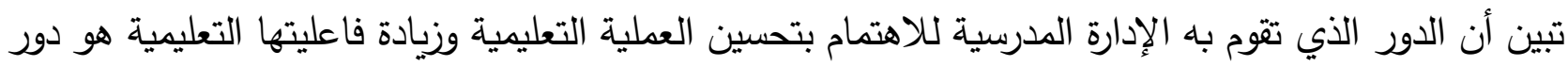

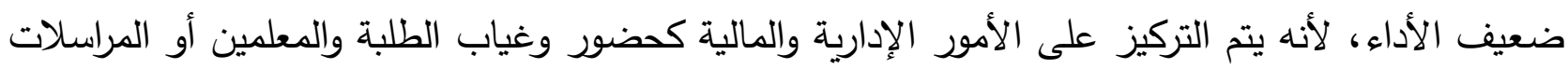

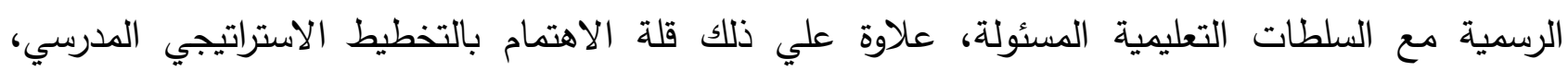

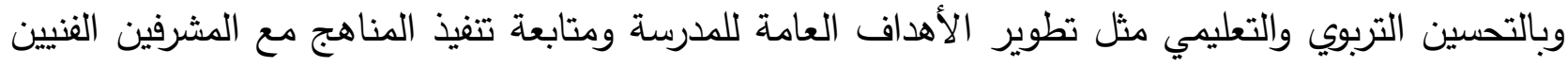

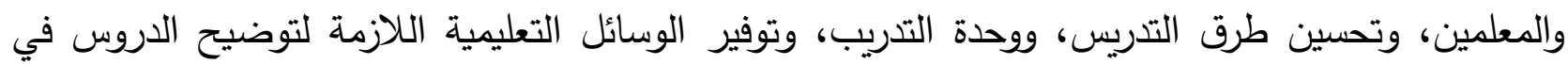
مختلف التخصصات، والمناخ التربوي المشجع علي عمليتي التعليم والتعلم.

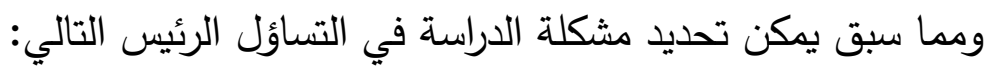

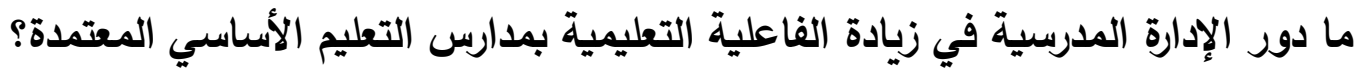
وينبثق منه التساؤلات الفرعية الآتية: 1- ما الأسس النظرية للإدارة المدرسية؟

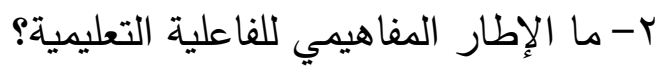
r- ما دور الإدارة المدرسية في مجال الفاعلية التعليمية بمدارس التعليم الأساسي المعتمدة؟

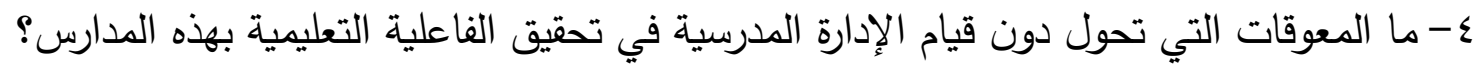

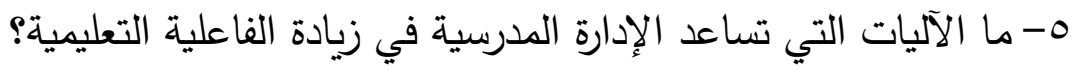

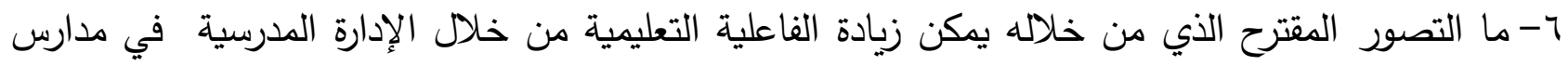

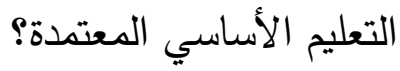

\section{أهداف الاراسةة:}

تهدف هذه الدراسة إلى ما يلي:

1- التعرف علي الأسس النظرية للإدارة المدرسية.

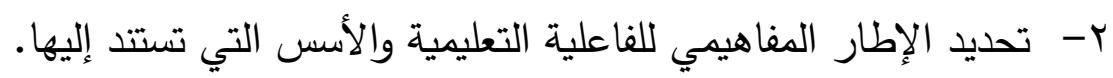
r- التعرف على دور الإدارة المدرسية في تحقيق الفاعلية التعليمية بمداس التعليم الأساسي المعتمدة. ع- إبراز المعوقات التي تحول دون قيام الإدارة الددرسية في تحقيق الفاعلية التعليمية بهذه الددارس. 
0- التعرف علي الآليات التي تساعد الإدارة الددرسية في زيادة الفاعلية التعليمية.

\section{أهمية الار اسةة: \\ تكمن أهمية الدراسة في الآتي: النياس}

1- أنها تعد الدراسة الأولي من نوعها التي تتناول دور الإدارة المدرسية في زيادة الفاعلية التعليمية بمدارس

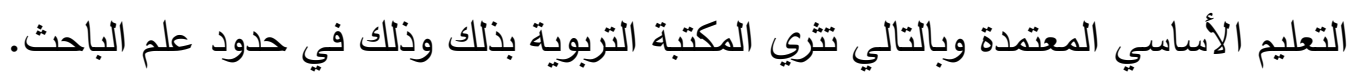

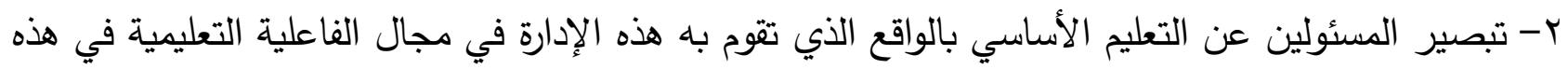
المدارس.

ب- تساعد المسئولين علي التعرف علي الآليات التي يمكن اتباعها لتحقيق هذا الدور في زيادة هدف الفاعلية التعليمية.

ع - إمداد الباحثين بدراسات ذات صلة بهذا الموضوع وفي مراحل تعليمية أخري. 0- أهمية الموضوع نفسه وهو الإدارة المدرسية ودورها الكبير في زيادة الفاعلية التعليمية بمدارس التعليم

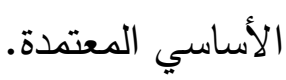

حدود الدراسة:

الحدود الموضوعية: تشمل الإطار المفاهيمي للإدارة المدرسية والفاعلية التعليمية. الحدود المكانية: مدارس التعليم الأساسي بمحافظة المنوفية. الحدود البشرية: مديري ومعلمي مدارس التعليم الأساسي بمحافظة المنوفية.

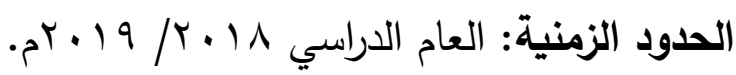
منهج الدراسة وأداتها: اعتمدت هذه الدراسة على المنهج الوصفي لملائمته لطبيعة وأهداف الدراسة، واعتمد الباحث في الحصول على

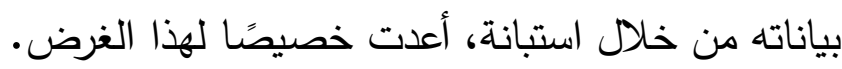
مجتمع وعينة الدراسة:

تكون مجتمع الدارسة من مدارس التعليم الأساسي (ابتدائي- إعدادي) الحكومية الرسمية بجميع الإدارات

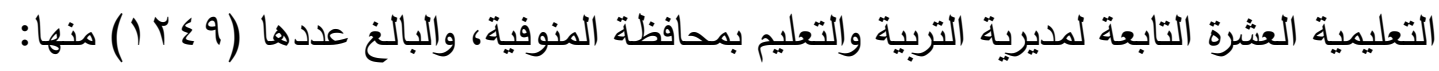

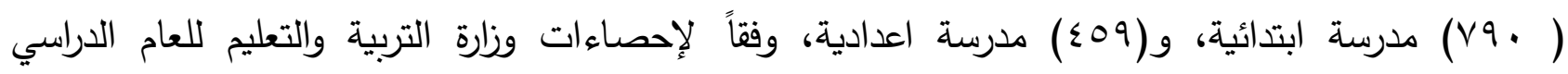

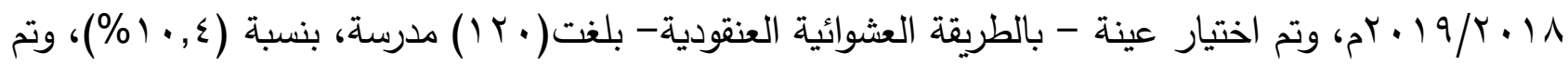

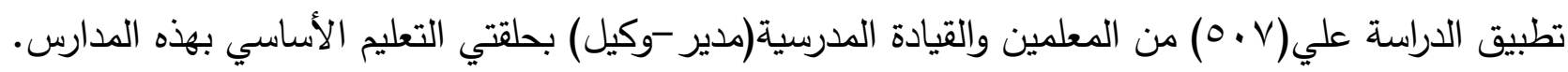
مصطات الاراسةة: (الاور(Role): (1) 
عرف(مرسي) (1) الدور بأنه مجموعة من الأنشطة المرتبطة، أو الأطر السلوكية التي تحقق ما هو متوقع في مواقف معينة وتترتب على الأدوار إمكانية التتبؤ بسلوك الفرد في المواقف المختلفة. وفي محاولة تعريف الدور توجد صعوبات حقيقية ذلك للحدودية البحث في مفهوم الدور في قواميس اللغة

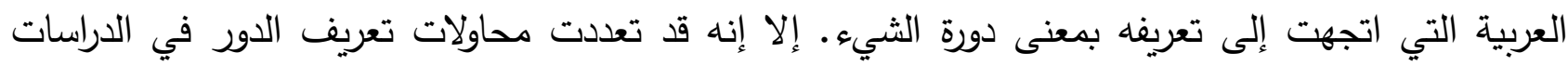

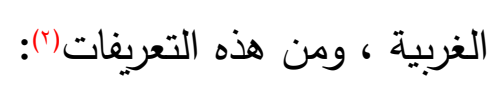
تعريف ليفي: يرى أن الدور هو بمثابة مركز متميز في نطاق بنيان اجتماعي معين.

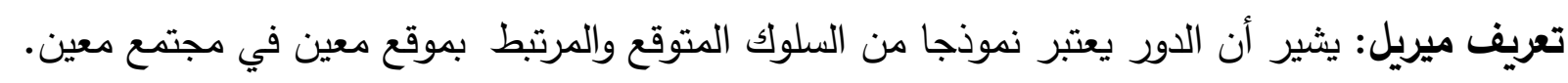

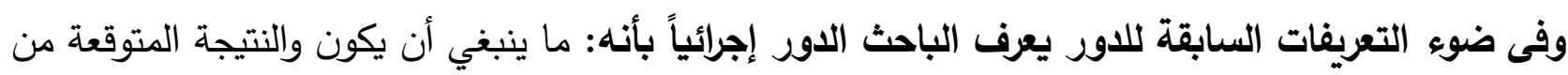

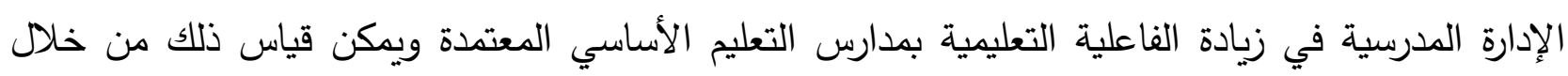

\section{r-الإدارة المدرسية)(The school administration):}

عرفها (العجمي)(r) بانها: جميع الجهود والأنشطة والعمليات من تخطيط، وتنظيم، ومتابعة وتوجيه ورقابة، والتي يقوم بها المدير مع العاملين معهاه من مدرسين وإداريين بغرض بناء وإعداد التلميذ من جميع النواحي (عقليًا،

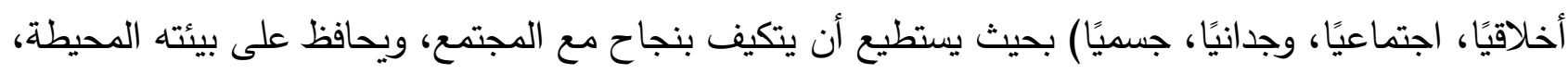
ويساهم في تقدم مجتمعه. كما عرفها (دياب) ()بأنها: جميع الجهود و الأنشطة و العطليات من (تخطيط، وتنظيم، ومتابعة ونوجيه، ورقابة)

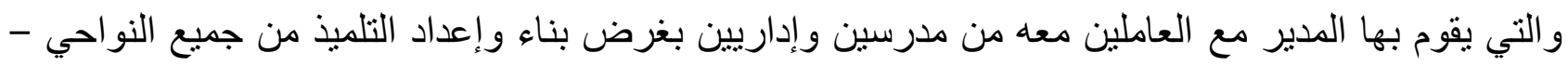

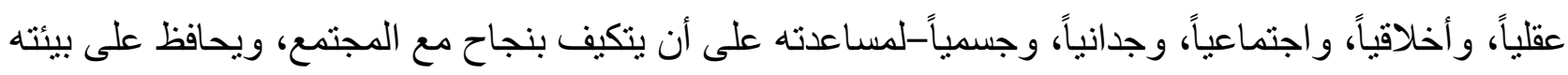
المحيطة، ويساهم في تقدم مجتمعه. وفي ضوء التعريفات السابقة يعرفها الباحث إجرائيا علي أنها: تلك الجهود المنظمة والمنسقة والمتسقة والهادفة

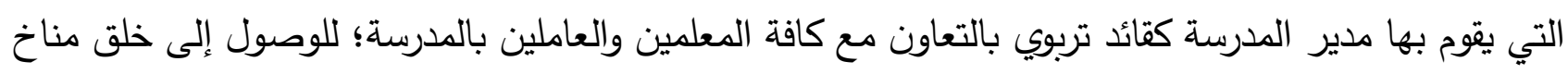

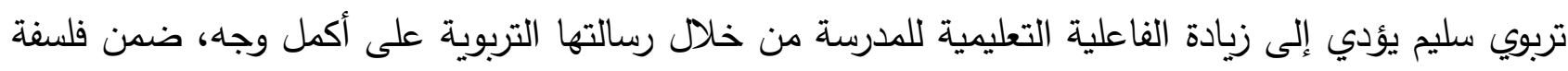
تربوية واضحة.

(2) www.elsyasi.com

(1) محمد منير مرسي( ( . ب). الإدارة المدرسية الدايثة، عالم الكتب، القاهرة، ص9 با.

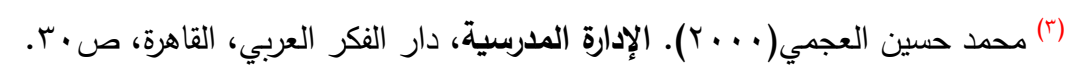

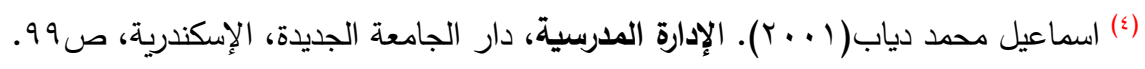




\section{r-الفاعلية التعليمية)(Educational effectiveness)}

تحقيق مخرجات عالية الجودة في ضوء رؤية المؤسسة التعليمية ورسالتها من خلال مجموعة العمليات التي

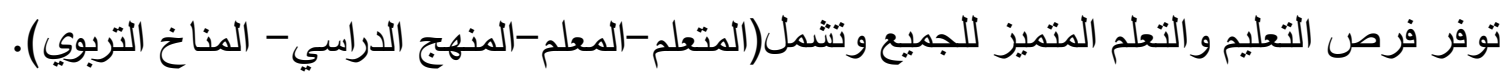
وعرفها إتزيوني(()(Etzioni): هي درجة تحقيق المؤسسة لأهدافها. في ضوء التعريفات السابقة يعرفها الباحث إجرائياً علي أنها:

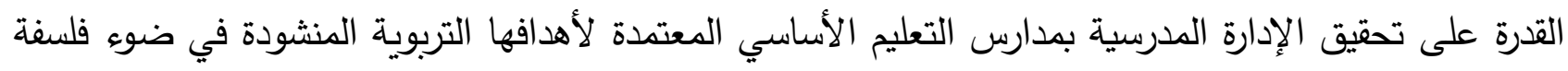

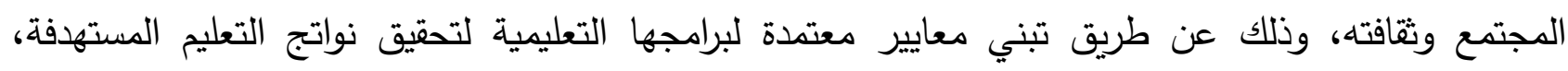
والالتزام بالعمل طبقاً لنظم ومعايير إدارة الجودة الثاملة. - المدارس المعتمدة(Approved schools): لم يعثر الباحث على تعريف محدد للمدارس بلمس

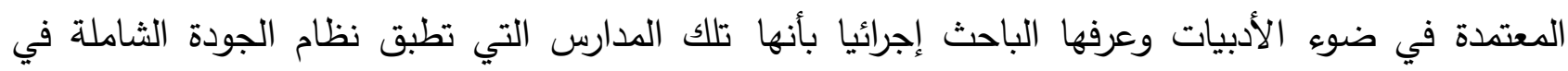

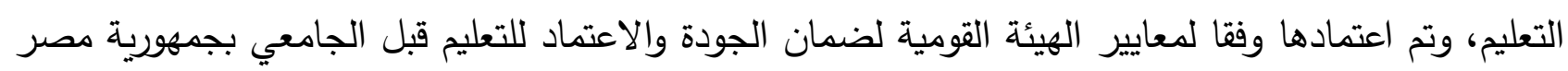
العربية. إجراءات الدراسةة: تتم إجراءات الاراسة على عدة خطوات كما يلي: 1- الاطلاع على البحوث والدراسات السابقة التي تتاولت الإدارة بشكل عام والإدارة الددرسية بشكل خاص. r- إعداد أداة الدراسة اعتماداً على الإطار النظري والدراسات السابقة.

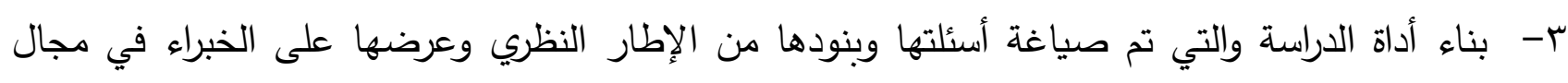
التعليم والأساتذة في كليات التربية. ع- اختيار عينة الدراسة وتطبيق الاستبانة.

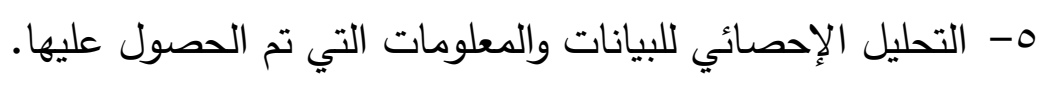
צ- ت تقسير نتائج الدراسة.

V - تقديم مجموعات من التوصيات من خلال النتائج التي سوف يتم التوصل إليها.

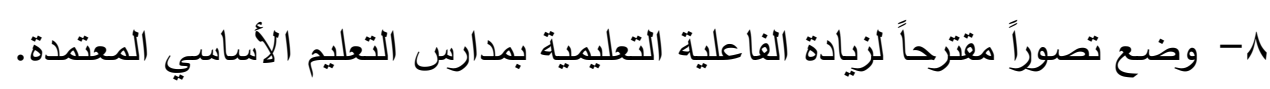
الاراسات السابقة:

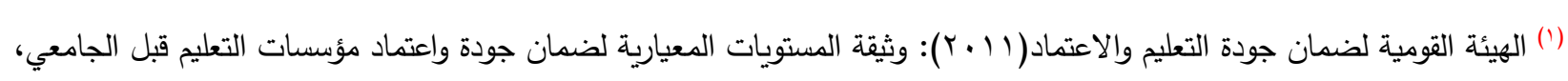

(2) http ://www. ahaidar@live.com.2/3/2018

مرحلة التعليم الأساسي، الإصدار الثالث، مصر ، صكان. 
أولاً- دراسة عمر أحمد عبدالغني المناعمة ():بعنوان(دور الإدارة المدرسية في المدارس الحكومية والمدارس الخاصة في محافظات غزة في تحسين العملية التعليمية).

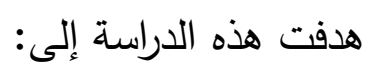
1-تحسين العملية التعليمية من خلال التعرف على دور الإدارة المدرسية في الدارس الحكومية والخاصة في تحسينها في محافظات غزة. r- التعرف على مدى مساهمة الإدارة الددرسية في نجاح العملية التعليمية في هذه الددارس.

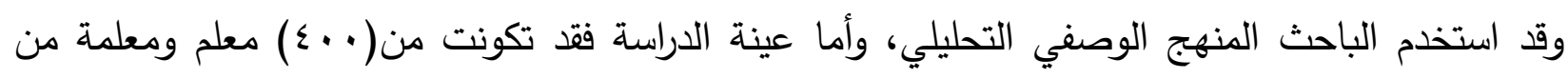

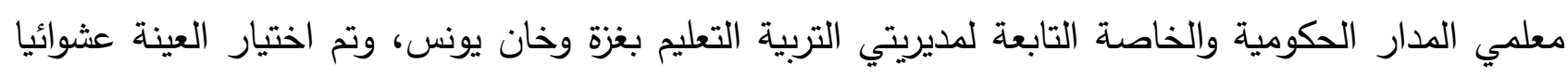

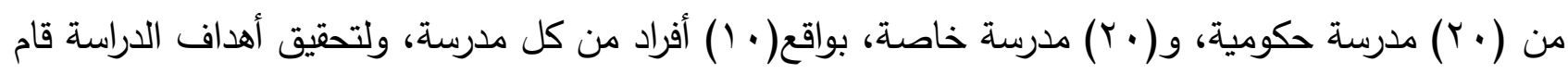

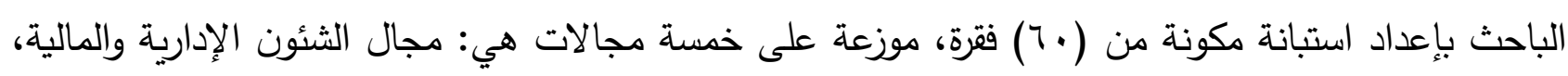

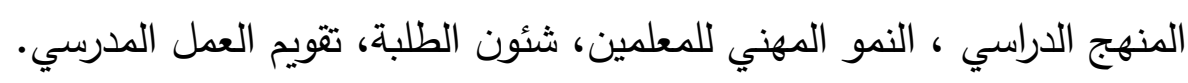
أوصت الدراسة بعدة توصيات منها: 1- التركيز على وجود قيم الجودة الثاملة التركيز على الجوانب الإنسانية والأخذ بمبدأ الثورى في الإدارة المدرسية. - (المكيز r- تنمية قدرات العاملين من خلال زيادة الاهتمام بالدورات التدريبية لمديري الدارس قبل العمل واثثاءه،

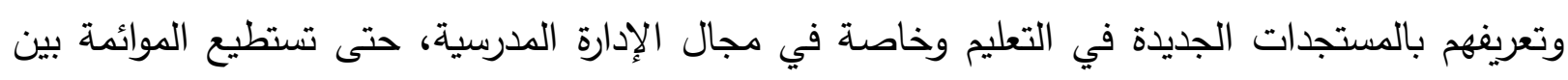
متطلبات إدارة المدرسة وبين المتغيرات المحلية والعالمية.

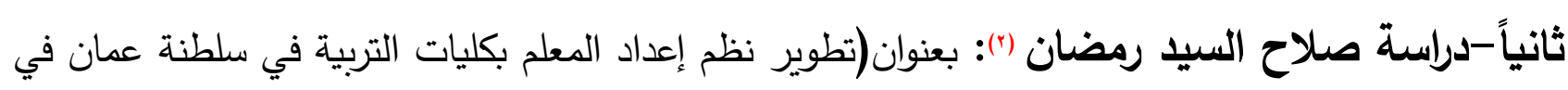
ضوء معايير الجودة الثاملة) هدفت الدراسة إلى: تحديد معايير الجودة الثاملة التي يمكن تطبيقها والاستفادة منها في نظام تكوين المعلم بكليات التربية في

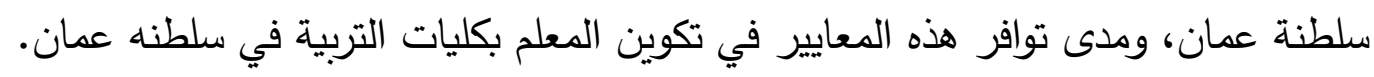
توصلت الدراسة إلى:

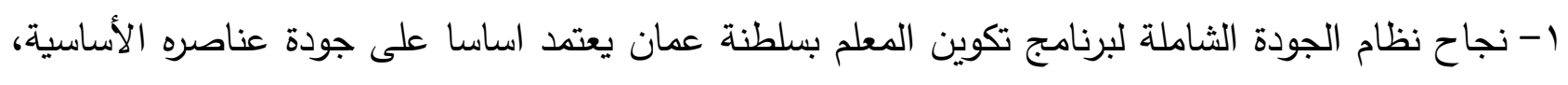
والمتمثلة في المدخلات والعمليات والمخرجات والتغذية الراجعة.

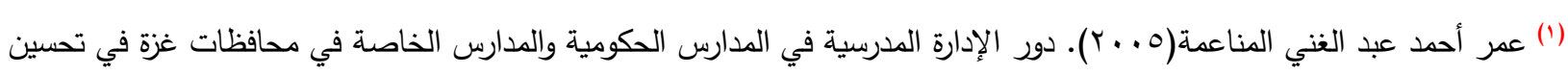

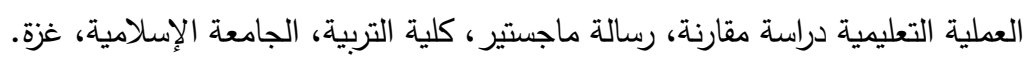

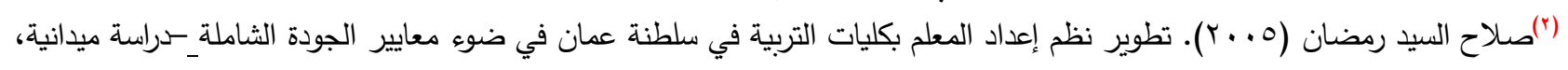


ץ- ضرورة إخضاع نظام تقويم أداء أعضاء هيئة التدريس لمعايير الجودة الثاملة. ثالثاً - دراسة عدنان بن احمد (1): بعنوان(مدى تقبل المعلمين لمعايير الجودة الثاملة في التعليم) هدفت الدراسة إلى: التعرف على مدى تقبل المعلمين لمعايير الجودة الثاملة في نظام التعليم بحافظة الإحساء، والعوامل التي

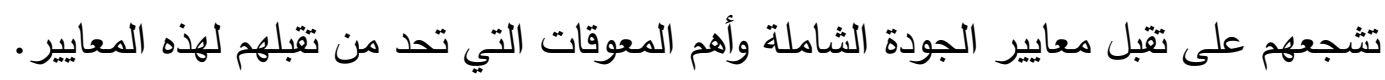
توصلت الدراسة الى العديد من النتائج اهمها:

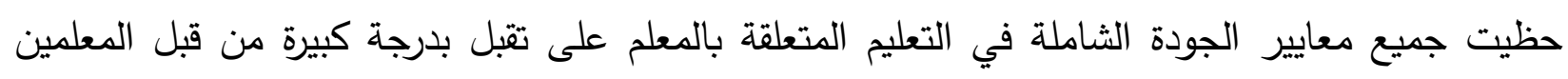

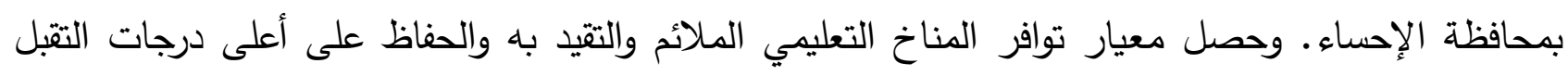
بالنسبة لبقية معايير الجودة الثاملة في التعليم.

رابعاً- دراسة درية السيد البنا (†):بعنوان(تطبيق بعض معايير الجودة الثاملة بالتعليم الثانوي الأزهري)

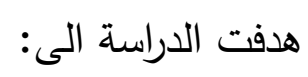

تحديد بعض المنطلبات التي قد تسهم في تطبيق معايير الجودة الثاملة في المعاهد الثانوية الأزهرية في مصر ، وإلقاء الضوء على واقع تطبيق بعض معايير الجودة الثاملة بمعاهد التعليم الأزهري بمحافظة الدقهلية. توصلت الدراسة إلى: عدم حصول عينة الدراسة على دورات تدريبية في المجال المهني أو عن الجودة، وإهمال العاملين وعدم

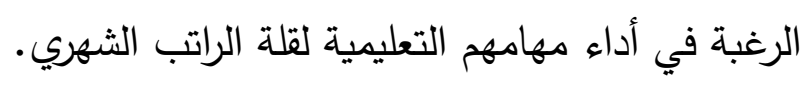
خامساً-دراسة عبد الحكيم محمد العطفي (·) : بعنوان(العوامل المؤثرة في وعي معلمي التعليم الأساسي لكفهوم الجودة في التعليم في ضوء الاتجاهات العالمية المعاصرة). هدفت الدراسة إلى: التعريف على مفهوم الجودة الثاملة في التعليم الأساسي والكثف عن العوامل المؤثرة في وعى معلمي التعليم

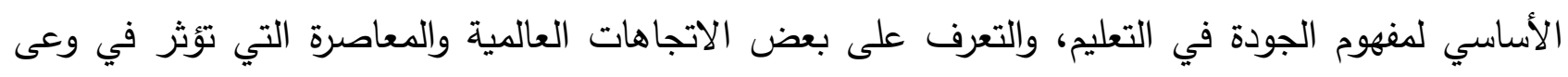
معلمي التعليم الأساسي لمفهوم الجودة.

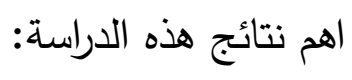

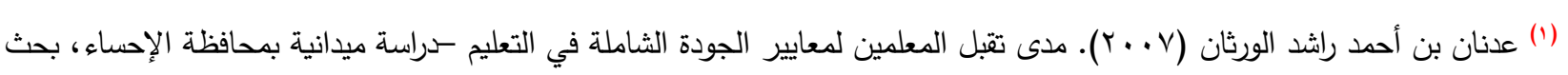
مقدم للقاء السنوي الرابع عشر (الجودة في التعليم العام)، الجمعية السعودية للعلوم التربوية من 10 - 17 - 17 مايو.

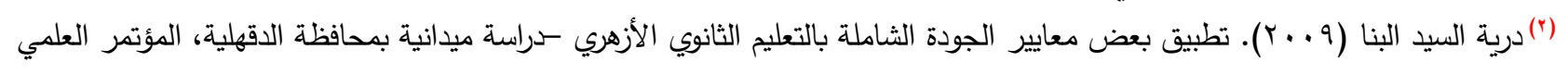

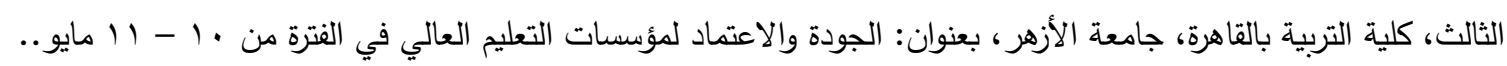

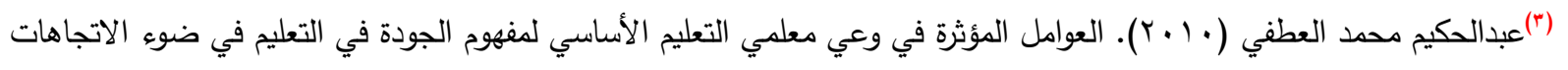
العالمية المعاصرة -دراسة ميدانية، رسالة دكتوراه غير منشورة، كلية التربية، جامعة الأزهر • 
قلة وعى بعض المعلمين والمعلمات بالتعليم الأساسي بمفهوم الجودة الثاملة، وأن الثقافة السائدة لدى

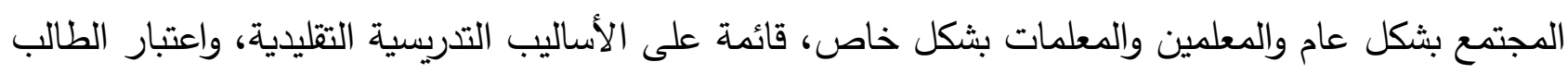
العنصر السلبى في العملية التعليمية. سادساً- دراسة: محمود أبو النور عبد الرسول (')بعنوان(علاقة المشاركة في صنع القرار بالأنماط القيادية لمديري المدارس الابتدائية في مصر ).

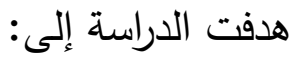

التعرف على العلاقة بين المشاركة في صنع القرار والأنماط القيادية لمديري المدارس الابتدائية في مصر . - استخدم الباحث المنهج الوصفي التحليلي. - أهم النتائج التي توصلت اليها الدراسة: 1-مستوى المشاركة في عملية صنع القرارات جاء متدنياً، وأن النمط الأوتوقراطي هو النمط السائد في الإدارة في معظم المدارس الابتدائية. ץ-وجود فروق ذات دلالة إحصائية بين استجابات أفراد العينة في محافظات الدراسة بما يؤكد وجود علاقة ارتباطية إيجابية بين مستوى المشاركة في صنع القرار على مستوى المدرسة والنمط القيادي للإدارة

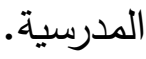
سـابعاً - دراسـة: ناصـر محمد العجميل(ب): بعنوان(درجة تطبيق مديري المدارس الثانوية والابتدائية في دولة الكويت للقيادة التثاركية من وجهة نظر المعلمين).

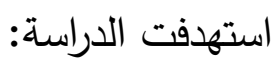
الكثف عن درجة تطبيق القيادة التثاركية لاى مديري المدارس الثانوية والابتدائية في دولة الكويت من وجهة

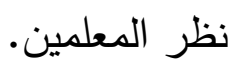
واستخدم الباحث المنهج الوصفين. توصلت الدراسة إلى:

1- أن درجة تطبيق مديري المدارس الثانويـة والابتدائية في دولـة الكويت للقيادة التشـاركية من وجهة نظر المعلمين كانت -بشكل عام مرتفعة.

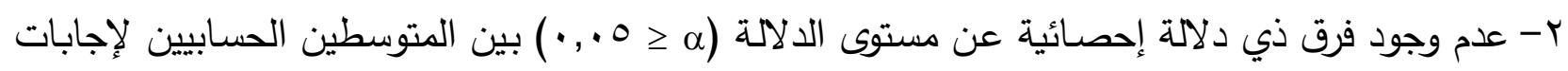
أفراد عينة الدراسة في المدارس الثانوية وفي الددارس الابتدائية.

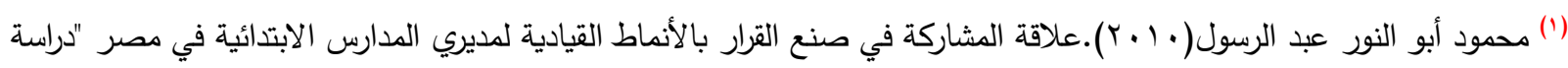

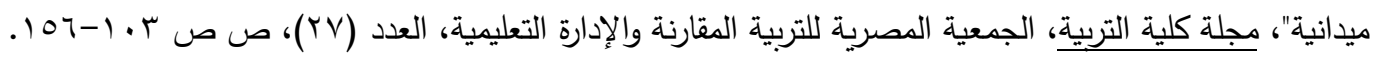

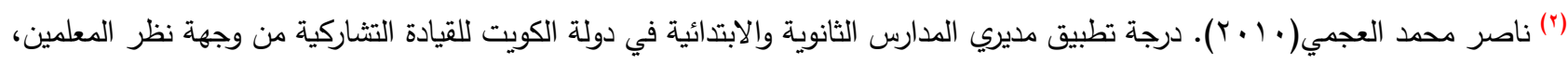

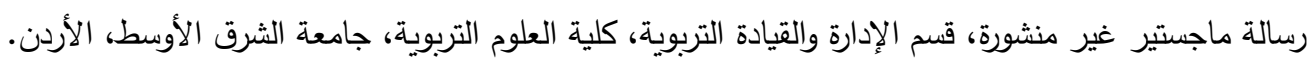




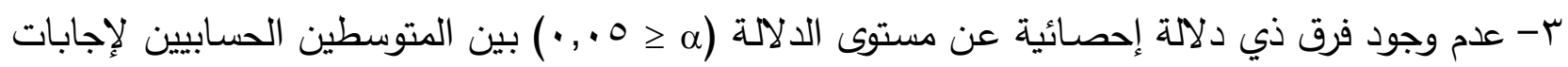
أفراد عينة الدراسة تبعاً للتغير الجنس والخبرة والمؤهل الدراسي. ثامناً - دراسة:جمال أحمد السيسي، وفتحي عشيبة (1):بعنوان(تقافة الجودة الثاملة بمدارس التعليم العام على ضوء تطبيق نظام ضمان جودة التعليم والاعتماد). هدفت الدراسة إلى:

الوصول لمفهوم ثقافة الجودة الثاملة وتحديد مكوناتها وأبعادها، والكشف عن مستوى ثقافة الجودة الثاملة

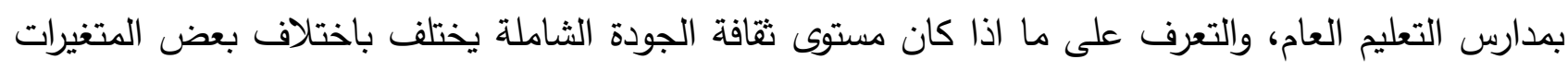
مثل حالة المدرسة( معتمدة، غير معتمدة)،( ريف، حضر )، وتقديم تصور مقترح لكان للارتقاء بثقافة الجودة الثاملة بمدارس التعليم العام.

استخدم الباحثان في دراستهما المنهج الوصفي، كما استخدما الاستبانة كأداة لجمع البيانات والمعلومات .

توصلت الدراسة الى مجموعة نتائج من أهمها:

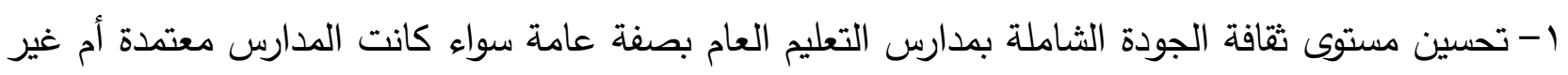
معتمدة، ريفية أم حضرية.

ז- أن بعد التصور العقلي هو أقل الأبعاد من حيث شيوع ثثقافة الجودة الثاملة، واحتل بعد الإمكانات المادية والبشرية المرتبة الأولى من حيث شيوع ثقافة الجودة الثاملة، كما احتل بعد القيادة الددرسية المرتبة الثانية من حيث شيوع ثقافة الجودة الثاملة. تاسعاً - دراسة: مشرف، وحامد ()(الصعوبات التي تواجه الإدارة المدرسية من وجهة نظر مديري المدارس) اعتمد البحث المنهج الوصفي، مجتمع الدراسة هو مديري ومديرات المدارس بالمستويين الأساس والثانوي بمحلية كادقلي، واختيرت العينة قصدية(rV) مدير ومديرة. هدفت الدراسة إلى: الى:

هدفت الدراسة إلي معرفة العقبات التي تواجه الإدارة الددرسية بمرحلتي الأساس والثانوي بمحلية كادقلي بولاية

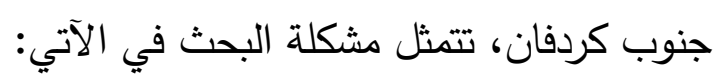
ا - أدت زيادة الطلاب والإقبال الثديد للالتحاق بالتعليم على المستوين الثاتين الأساسي والثانوي لافتتاح مدارس بكل المناطق مما أدى لزيادة عدد المعلمين. r- هذه الزيادة أظهرت بعض ادى لميادة المشكلات أمام العمل الإداري في تلك المدارس.

(1) جمال أحمد السيسي، فتحي درويش عشيبة( (1 +r). ثقافة الجودة الثاملة بدارس التعليم العام على ضوء تطبيق نظام ضمان جودة التعليم

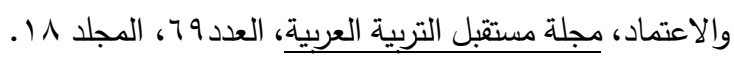

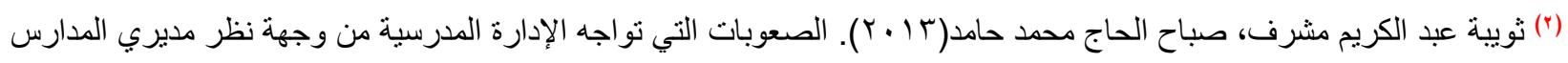
دراسة ميدانية، محلية كادقلي بو لاية جنوب كردفان، جامعة السودان للعلوم والنكنولوجيا. 
توصلت الدر اسة للنتائج التالية: ا- أن الإدارة التعليمية لا توفر للإدارة المدرسية ميزانية سنوية ووسائل تقنية كما أنها لا تحفز المعلم والطالب

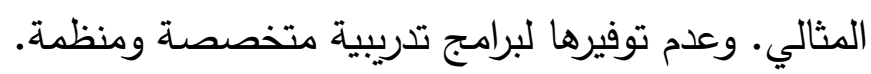
r- عدم استطاعة المعلم لمتابعة جميع الطلاب بالفصل وواجباتهم المنزلية والمعلمين غير مدربين وتكثر تتقلاتهم أثناء العام الدراسي. r- عدم متابعة أولياء الأمور لدراسة أبنائهم بالمدرسة.

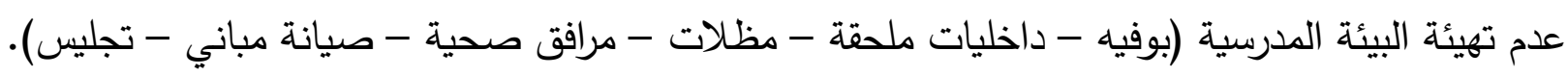

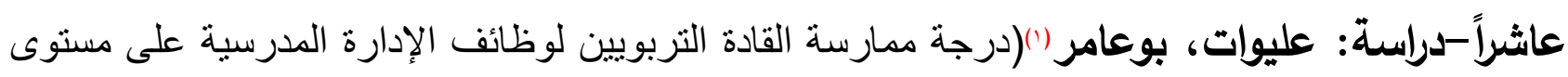

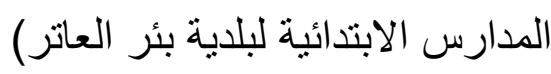
هدفت الدراسة إلى: صياغة فرضيات إجرائية لذات الغرض تمثلت في فرضيتين عامتين الأولى حول ممارسة القادة التربويين لوظائف الإدارة التربوية بمجالاتها الستة ( التخطيط، التنظيم، التوجيه، الرقابة اتخاذ الترارات والتيقييم)، والثانية حول الاختلاف في درجة ممارسة القادة التزبويين لوظائف الإدارة المدرسية على مستوى المدارس الابتدائية الذي لتئي يعزى إلى متغيري المؤهل العلمي و الخبرة.

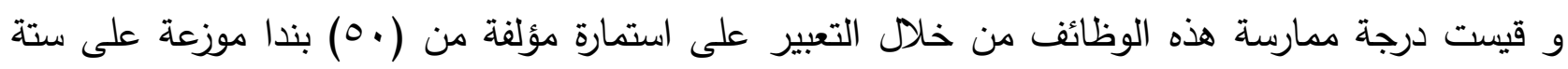

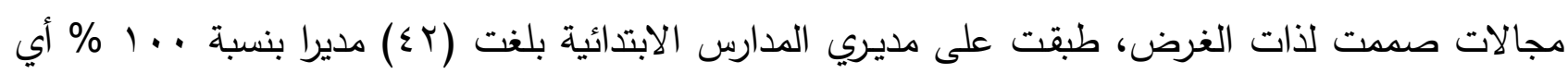
مسح شامل للمجتمع الأصلي اختيروا بطريقة قصدية. توصلت الدر اسة للنتائج التالية: لم تكشفت نتائج الدراسة عن اختلاف واضح حول درجة ممارسة مديري المدارس الابتدائية لوظائف الإدارة

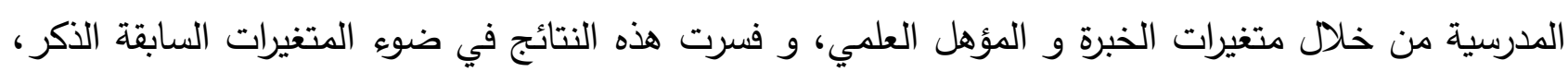

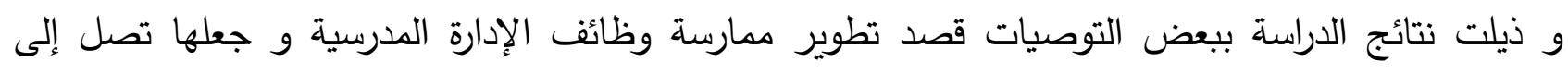

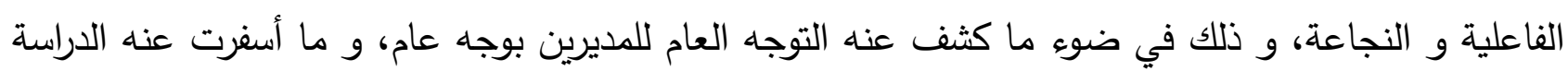
الميدانية من نتائج حسب المتغيرات. حادي عشر - دراسة: عبد الرحمن، أخرون ()(دور الإدارة المدرسية في تحقيق أهداف مرحلة الأساس) هدفت الدراسة إلى: بيان كيفية عمل الإدارة المدرسية في تحقيق أهداف مرحلة الأساس وتوضيح الفوائد المترتبة على تحقيق أهداف الفال

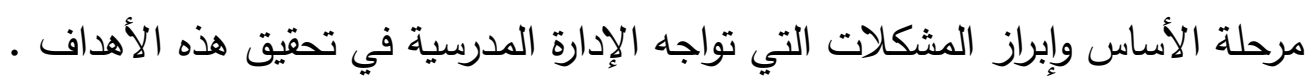

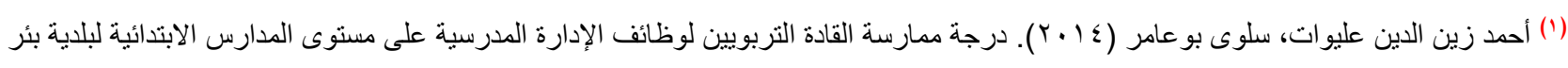

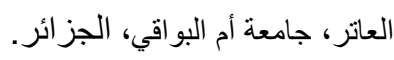

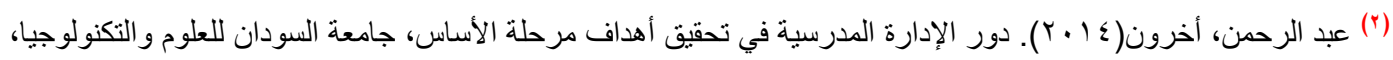


ويتكون مجتمع البحث من معلمي ومعلمات مرحلة الأساس بوحدة الخرطوم قطاع شمال موزعين ويبلغ عددهم

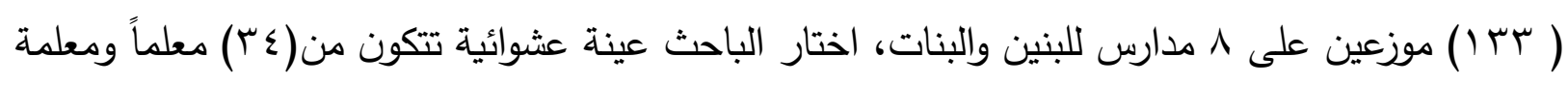

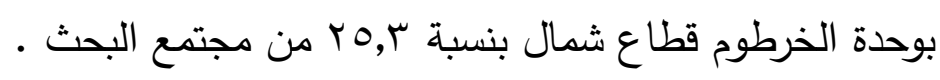
استخدم الباحث المنهج الوصفي والإدارة كانت الاستبانة. توصلت الدر اسة للنتائج التالية: 1- إدداد المدرسة يعمل على تحقيق أهداف مرحلة الأساس بثكل جيد. r- إن لتحقيق أهداف مرحلة الأساس فوائد كبيرة من أهمها أ- - تحقيق تكامل بين العلم والعمل. ب- - إعداد مواطن متوافق مع مجتمعه.

ت- امتلاك التلاميذ للقيم الاجتماعية التي تعكس أهداف المجتمع.

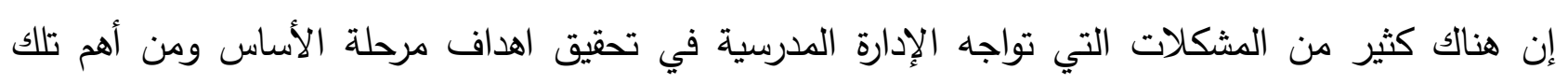
المشكلات، قلة الدعم المادي.

ثاني عشر -- دراسة: قرواني"(دور الإدارة المدرسية في إيجاد بيئة مدرسية مشوقة في مدارس فلسطين : محافظة سلفيت أنموذجا) هدفت الدراسة إلى: الكثف عن دور الإدارة المدرسية في إيجاد بيئة مدرسية مشوقة في مدارس فلسطين من وجهة نظر المعلمين

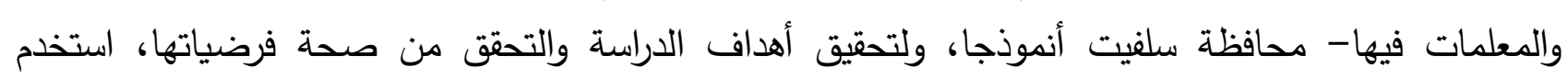

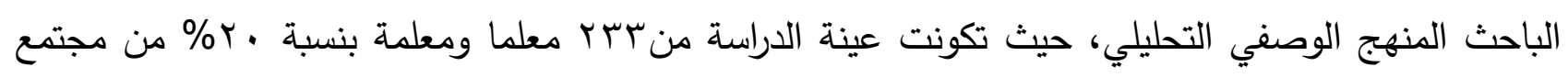
الدراسة الذين وزعت عليهم استبانة لجمع البيانات اللازمة. توصلت الدراسة للنتائج التالية: يوجد دور كبير للإدارة المدرسية في خلق بيئة مدرسية مشوقة في مدارس محافظة سلفيت من وجهة نظر

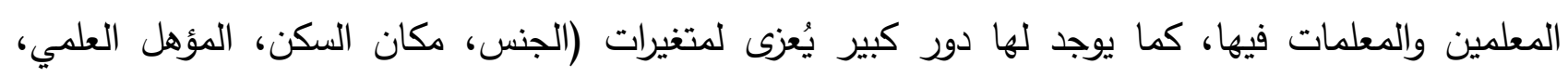

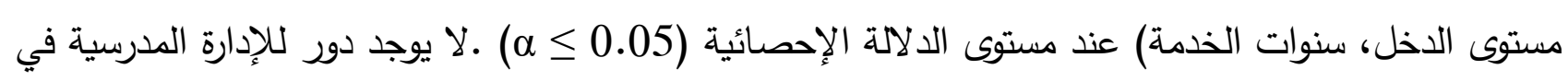

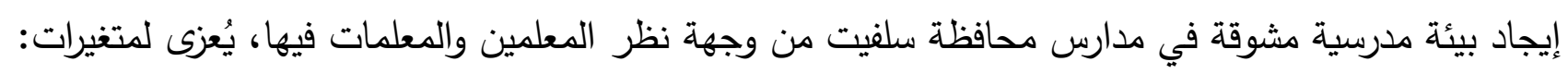

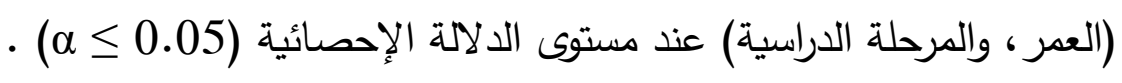

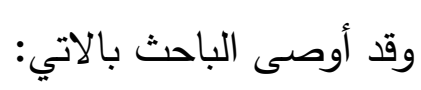


بتظيم ورشات عمل وعقد ندوات في المدارس حول مفاهيم إدارة الصف الحديثة والتعامل مع الطلبة في المدرسة وأهمية التواصل بين الإدارة المدرسية والمعلمين من جهة وبين أولياء أمور الطلبة من جهة أخرى، وتثجيع الطلبة على تتظيم نثاطات مشتركة تجمع بين الطلبة والمعلمين وإدارة المدرسة.

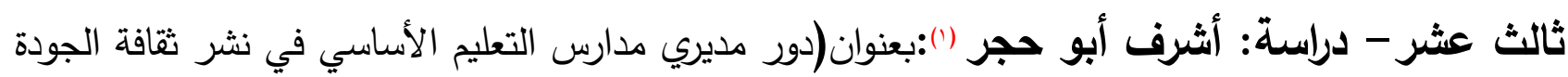

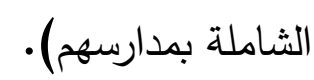

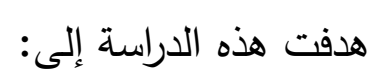
تفعيل دور مديري مدارس التعليم الأساسي في نشر ثقافة الجودة الثاملة، وذلك من خلال توضيح مفهوم ثقافة الجودة الثاملة، وبيان أهم خصائصها، ومكوناتها، والمتطلبات اللازمة لنشرها. وقد استخدم الباحث المنهج الوصفي واستخدم أداة الاستبانة.

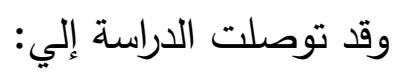

1- تحديد الدور الذي ينبغي أن يقوم به مديري المدارس لنشر ثقافة الجودة الثاملة. r- الكثف عن واقع قيام مديري المدارس بدورهم في نشر ثقافة الجودة الثاملة.

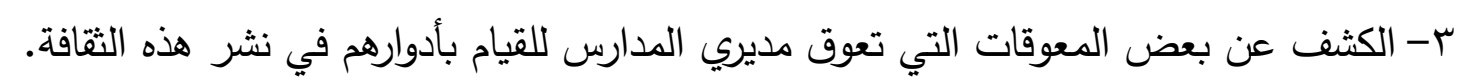
التعليق على الدراسات السابقة: من خلال إطلاع الباحث على الدراسات السابقة العربية منها والأجنبية فوجد أنها استهدفت الإدارة المدرسية بشكل عام، ومدير المدرسة بشكل خاص، لوضع تصور لإدارة مدرسية تكون قادرة على قيادة وإدارة المدرسة الإدات

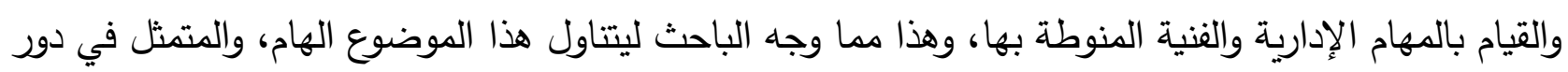

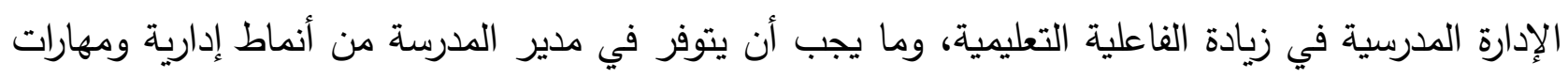

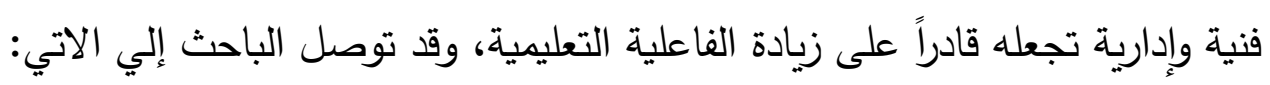

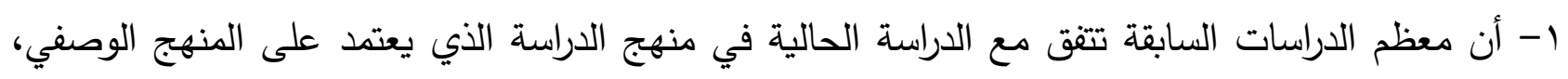

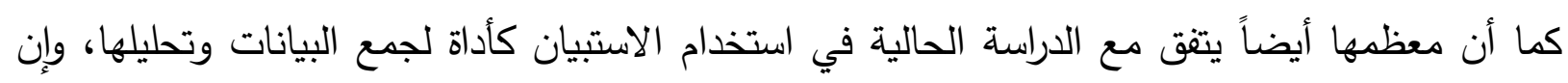
كانت بعض الدراسات قد اعتمدت على المقابلات الثخصية للمعلمين والعاملين.

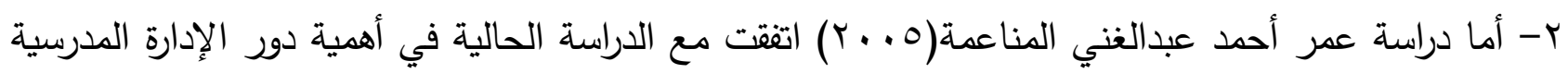

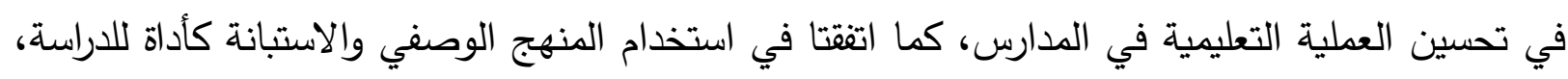
واختلفتا في أن الدراسة السابقة تكثف عن واقع الإلية فئدارة المدرسية و مدى مساهمتها في نجاح العملية التعليمية، بينما الدراسة الحالية تكثف عن واقع قيام مديري المدارس بأدوارهم في زيادة مجال الفاعلية التعليمية في مدارس التعليم الأساسي المعتمدة.

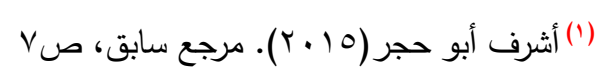




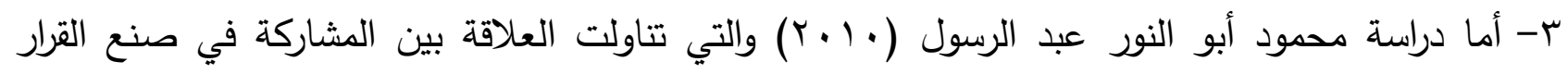

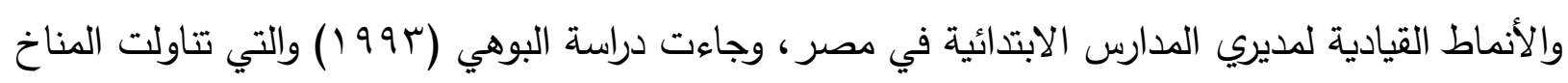

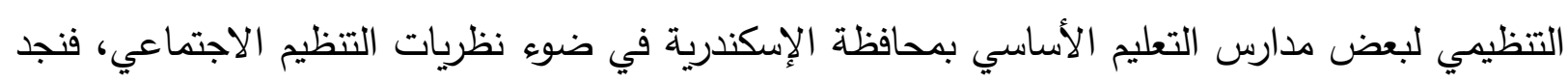

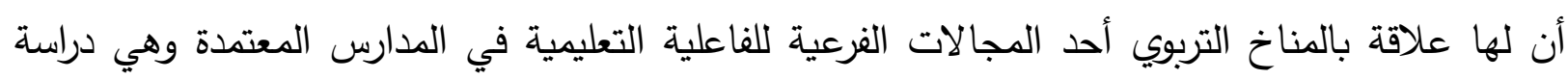
قديمة نسبياً حيث تمت منذ م⿸ كام، أما باقي الدراسات فهي إما عربية أو أجنبية.

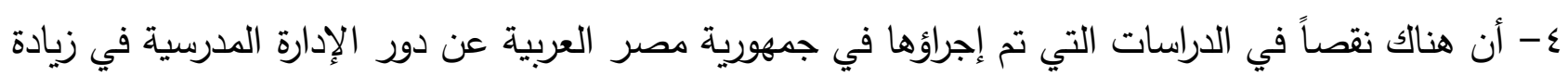

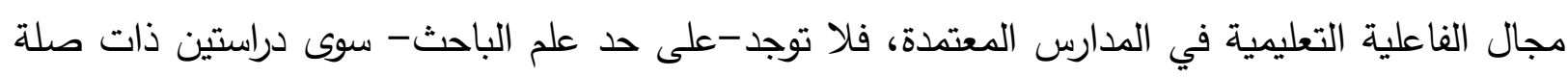

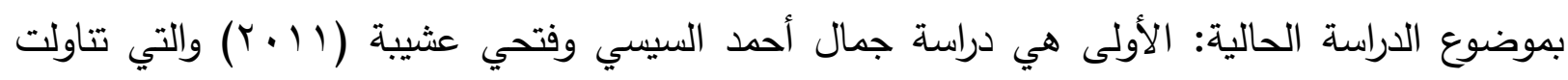

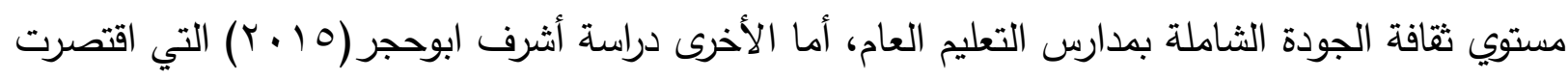
علي دور مديري مدارس التعليم الاساسي في نشر ثقافة الجودة.

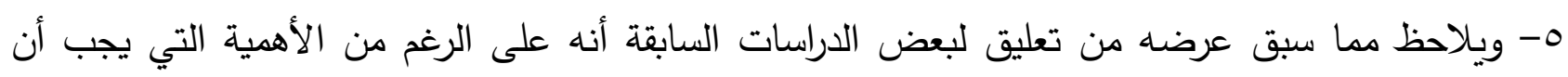

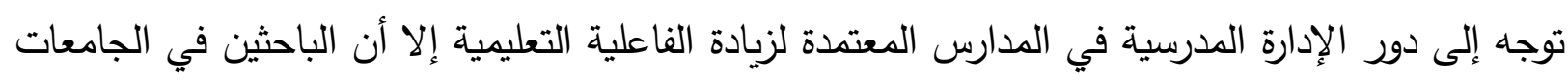
المصرية لم يوجهوا اهتمامهم إلى هذا الموضوع.

\section{وقد تثابهت الدراسة الحالية مع الاراسات السابقة في عدة نقاط منها :}

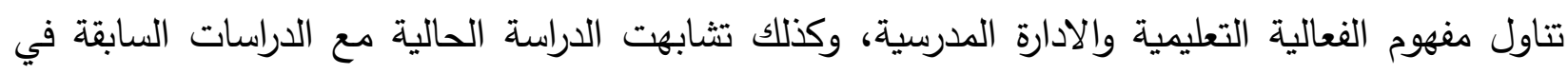

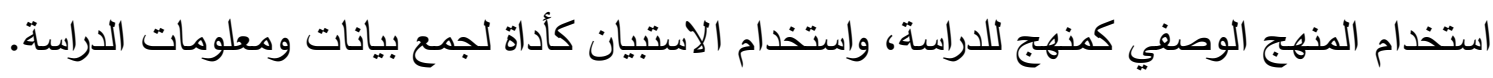

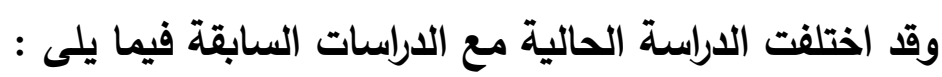

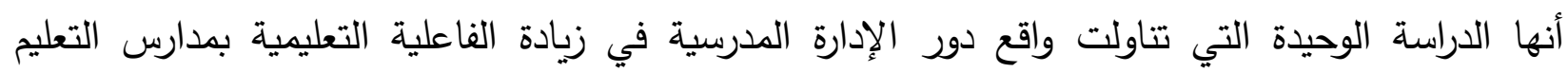

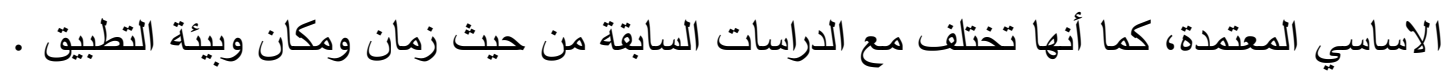
وقد استفادت الدراسة الحالية من الدراسات السابقة فيما يلى : الجانب النظري : من خلال تكوين خلفية نظرية للدراسة وإلقاء الضوه على الإطار الدفاهيمي لكل من الفعالية التعليمية والتعرف على واقع دور الادارة المدرسية بمداس التعليم الاساسي المعتمدة.

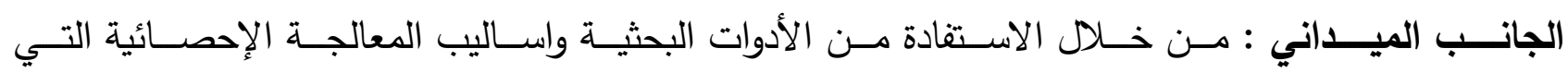

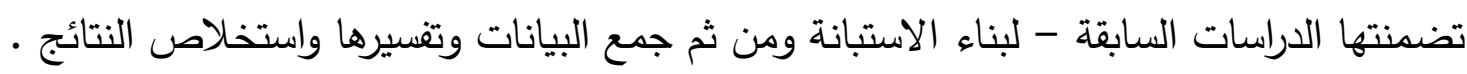

\section{وسوف تستفيد الاراسة الحالية من الدراسات السابقة في:}

- الجانب النظري: عن طريق تكوين خلفية نظرية للدراسة وإلقاء الضوء على الأسس النظرية للإدارة المدرسية مفهومها وخصائصها وعناصرها، وإلقاء الضوه على نلى الفاعلية التعليمية. 
- الجانب الميداني: عن طريق الاستفادة من الأدوات البحثية التي تضمنتها هذه الدراسات وكيفية إعدادها

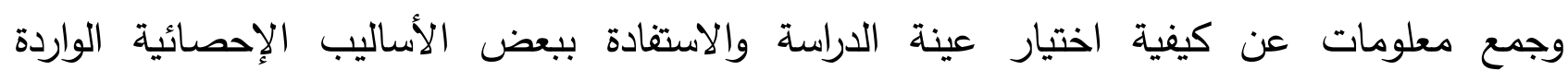
لاستخلاص نتائج الدراسة وتفسيرها وكيفية بناء التصور المقترح. ويتضح من عرض الدراسات السابقة أنه لا توجد دراسة تناولت الفاعلية التعليمية بمدارس التعليم الأساسي، ومن هنا جاءت هذه الدراسة الراهنة التي تسعى إلى الكثف عن عند واقع دور الإدارة المدرسية بمدارس التعليم الأساسي المعتمدة، والتعرف على المعوقات التي قد تعوقهم، وكيفية التغلب عليها، وتقديم تصور مقترح لزيادة مستوى الفاعلية التعليمية لديهم.

\section{نتائَج الدراسية:}

\section{توصلت الاراسة في جانبها الميداني لعدة نتائج من أهمها:}

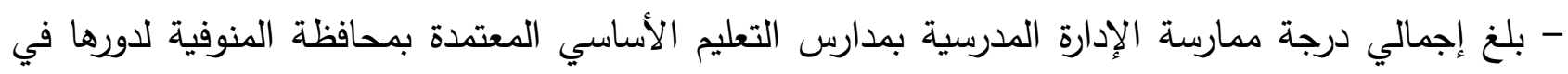

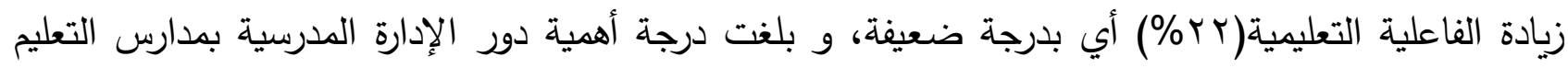

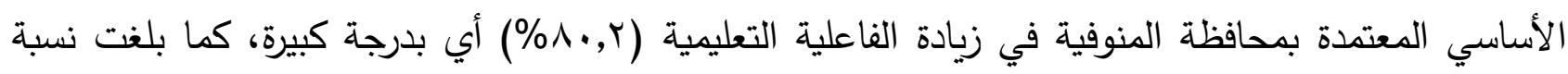

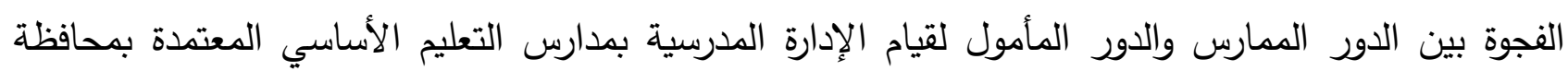

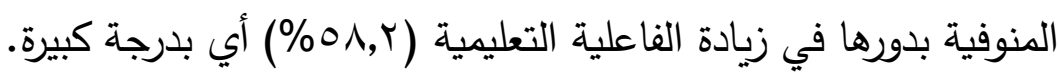

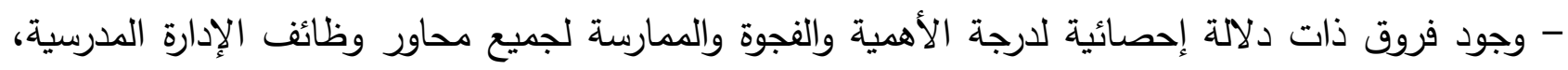

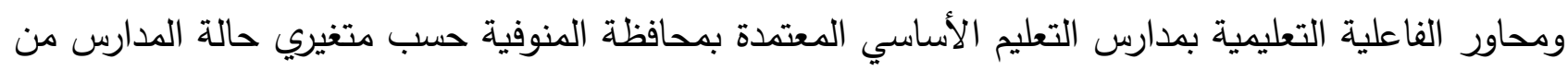
الاعتماد لصالح فئة (معتمدة)، والوظيفة لصالح فئة (معلم). - لا توجد فروق ذات دلالة لدرجة الأهمية والفجوة والممارسة لجميع محاور وظائف الهمائف الإدارة المدرسية، ومحاور

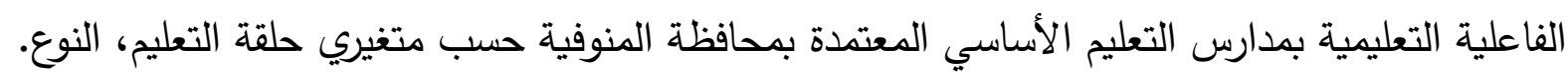
-وجود درجة كبيرة للفجوة والأهمية في جميع محاور وظائف الإدارة الددرسية حسب جميع متغيرات الدراسة خاصة في محوري التخطيط وصنع القرار • - وجود درجة ضعيفة للممارسة في جميع محاور وظائف الإدارة الددرسية حسب جميع متغيرات الدراسة خاصة في محوري التخطيط وصنع القرار. - وجود درجة كبيرة للفجوة والأهمية في جميع محاور الفاعلية التعليمية بمدارس التعليم الأساسي المعتمدة بمحافظة المنوفية خاصة في محوري المعلم والمناخ التربوي. - وجود درجة ضعيفة للممارسة في جميع محاور الفاعلية التعليمية بمدارس التعليم الأساسي المعتمدة بمحافظة المنوفية خاصة في محوري المتعلم والمعلم. 


\section{المراجع}

اولاً: المراجيح العربية

ا- الخطيب رداح وآخرون( . . ب؟). الإدارة والإثراف التربوي اتجاهات حديثة، دار الأمل، الأردن.

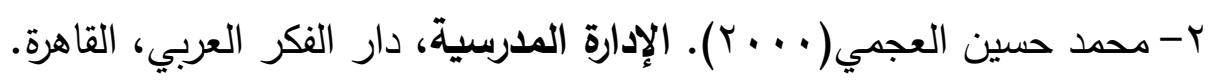

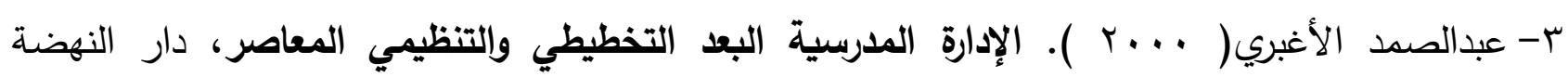
العربية، بيروت.

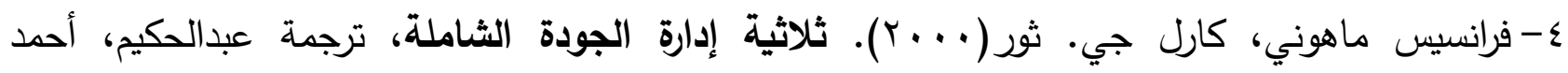

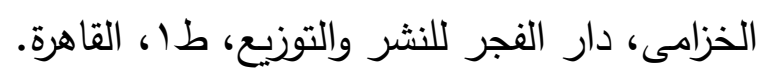

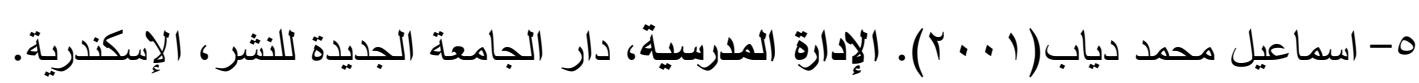

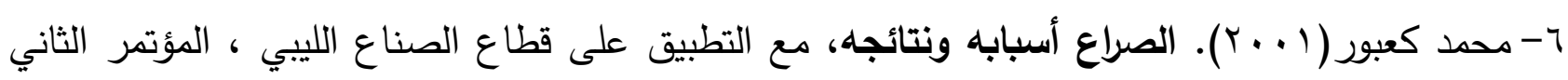
للإدارة العربية القاهرة.

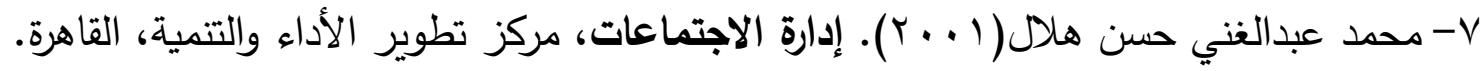

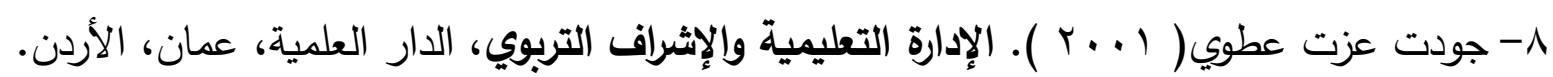

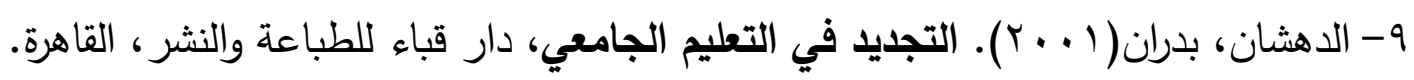

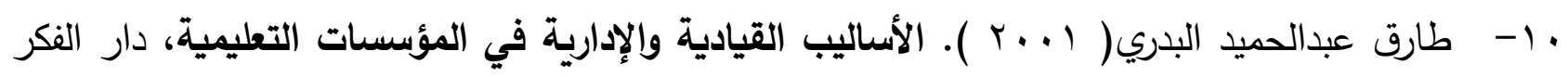
للطباعة، عمان.

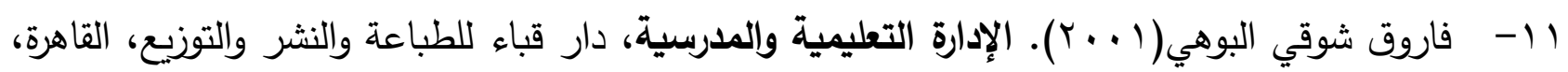
مصر

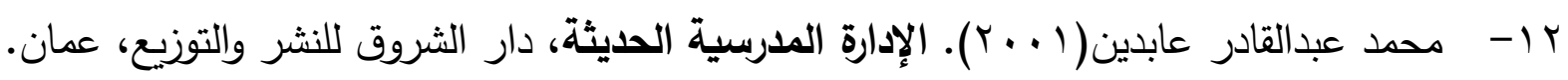

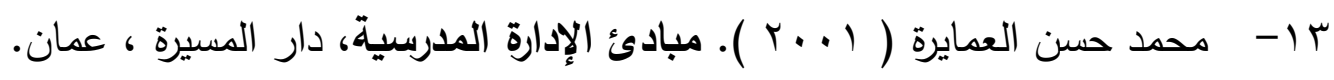

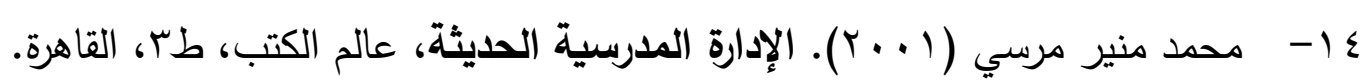

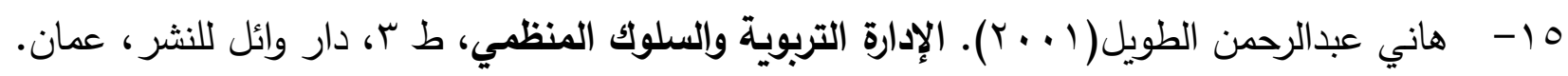

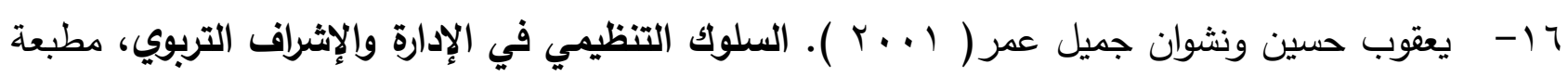
دار المنارة، غزة.

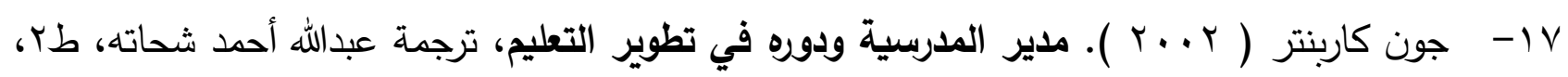
إيتراك للنشر والتوزيع، القاهرة.

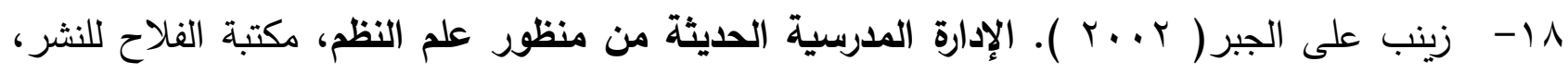
الكويت. 
9 19- صلاح عبد الحميد مصطفى( r .. r ). الإدارة المدرسية في ضوء الفكر الإداري المعاصر، دار المريخ للنشر ، الرياض.

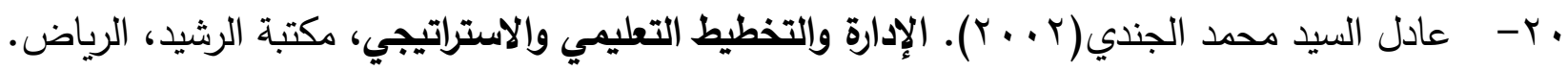

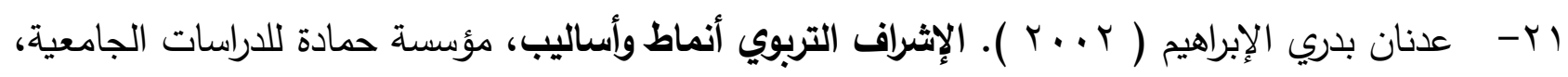
الأردن.

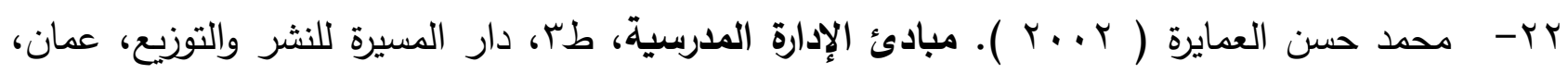
الأردن.

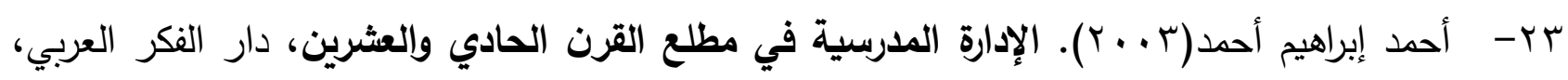
القاهرة.

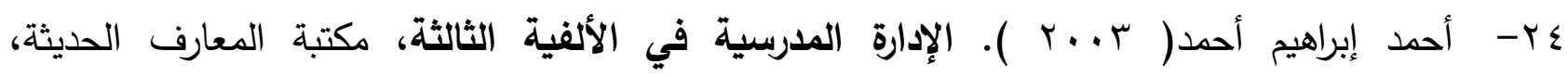
الإسكندرية.

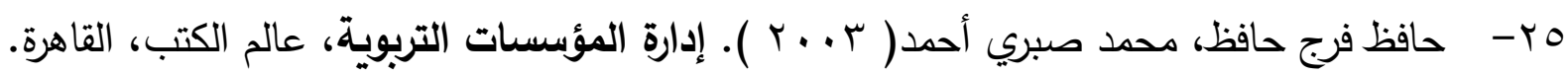

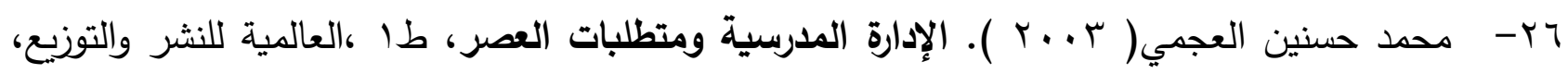
مصر

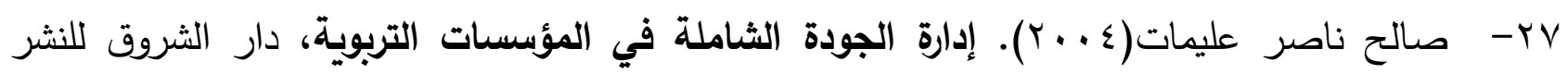
والتوزيع، طا، القاهرة.

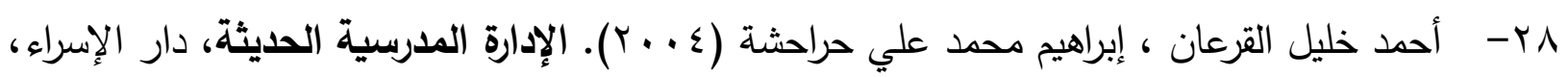
عمان، الأردن.

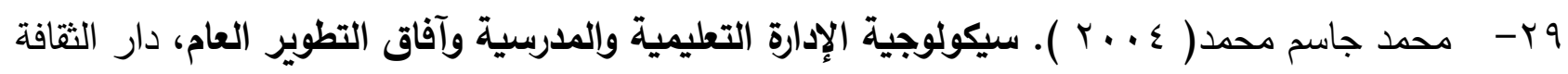
لـنشر والتوزيع، الأردن. • ץ- محمد طافش( ؟ . . ؟ ). الإبداع في الإثراف التربوي والإدارة المدرسية، دار الفرقان، عمان، الاردن، صזr.

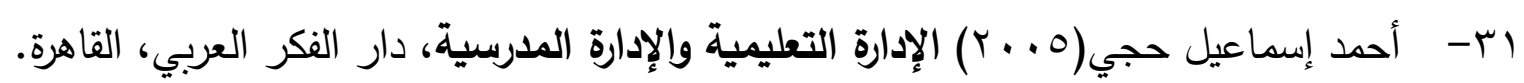

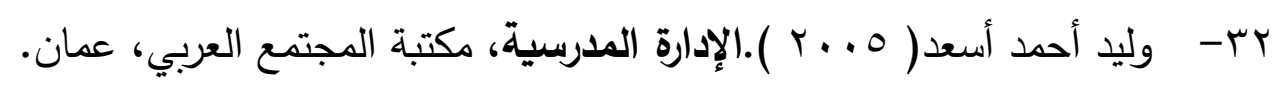

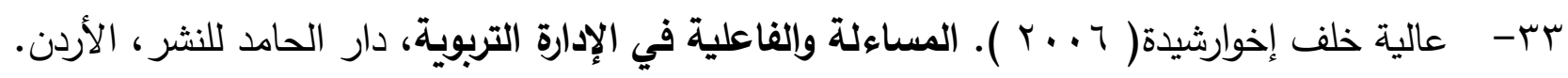

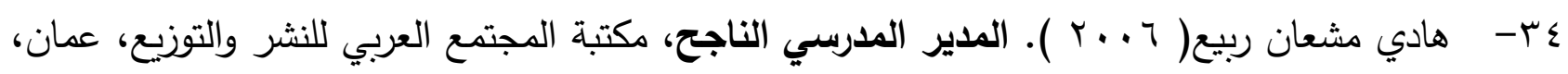
الأردن.

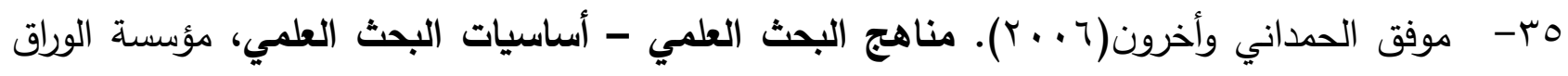
للنشر، عمان. 


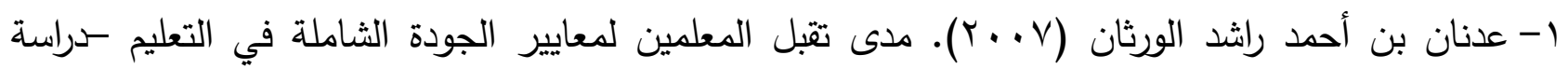
ميدانية بمحافظة الإحساء، بحث مقدم للقاء السنوي الرابع عشر (الجودة في التعليم العام)، الجمعية لئيل

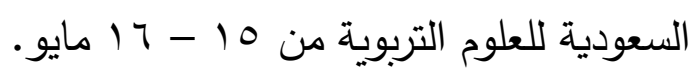

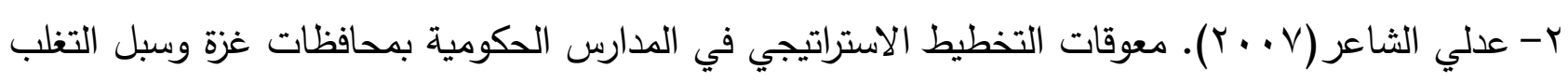

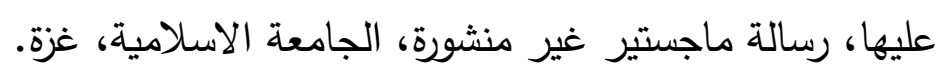

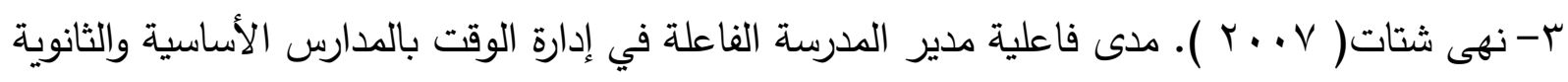

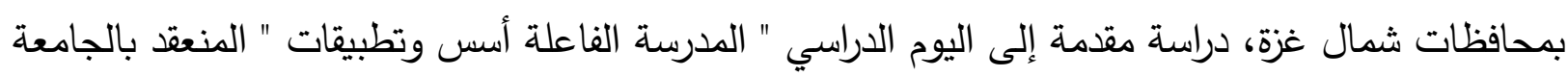
الإسلامية، غزة.

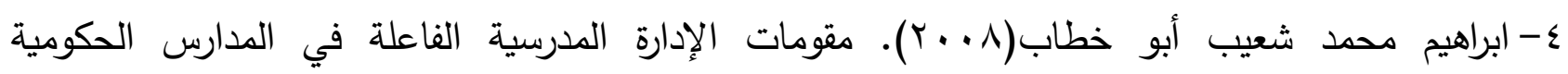

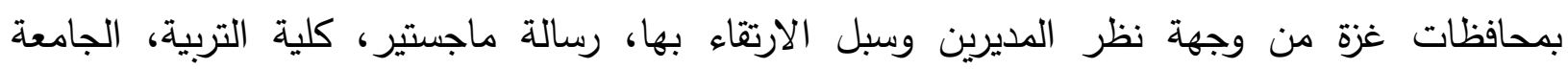

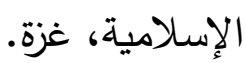

0- ريم علي المغربي (^ . . ب). الفاعلية الذاتية التعليمية لـعلمي العلوم في المرحلة الأساسية وعلاقتها بالفاعلية الذاتية التعلمية لطلبتهم وتحصيلهم العلمي، رسالة دكتوراه، كلية الدراسات العليا، الجامعة الأردنية، الأردن.

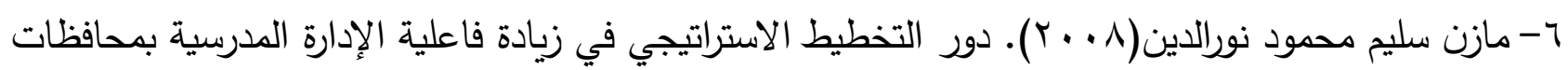
غزة، رسالة ماجستير غير منشورة، الجامعة الاسلامية، غزة.

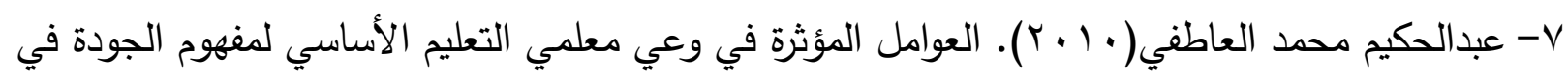
التعليم في ضوء الاتجاهات العالمية المعاصرة سراسة ميدانية، رسالة دكتوراه غير منشورة، كلية التربية، جامعة الأزهر .

\section{ثالثاً: المراجع والدوريات الأجنبية.}

1- Shore , L.M. \& Wayne, S.J. Commitment and employee behavior (1993

2- Nickels , W.G., et al.,(1999). understanding Business, New York , McGraw -Hill., pp.456.

3- Robbins ,Stephen \&Coulter ,Mary (1999) ." Management 6th ed .m",Upper Saddle River, New Jersey ,Prentice Hall.

4- Wolfolk Hoy and Spero (2000). Changes In Teacher Efficacy During The Eary years of Teaching, paper presented at the annul meeting of the American Educational Research Association, New Orlens LA. Session43:22, Qualitative and Quantitative Approaches to Examining and Learning, April28.

5- New south wales Department of Education and Training(2000). Australia leading and Managing the school, Report 3, June, p p 62- 63. 
6- Charles Hoy And Colin Boyne(2000). Improving Quality In Education, Flamer Press, London, P 120.

7- Office for standards in Education in England(2001). School covernance, Making it Better",Areport form the office of Her Majesty's chref Inspeckor of schools, Ceown copyright, london, pp 32- 33.

8- Mormon R.H. et al(2001): Does perceived organizational support mediate the relationship between procedural justice and organizational citizenship behavior?" Academy of management journal, Vol.44, pp351-357.

9- Kathleen Cotton (2001): applying total quality management principles to secondary education school improvement research services (SIRS), the office of education research and improvement U.S.

10- Patsy. E Johnson, Susan(2001). J. Scolly Leader power and social Inf Luence in the vertical team, Journal of Educational Administration, vol 39, Noll, P 47.

11- Quin, David M.(2002). The impact of principal leadership behaviors on instructional practice and student engagement, Journal of Educational Administration, No.(5), Vol.(40).

12- $\quad$ Silins, Halia and Muford, Bill. (2002). Schools as learning organization, Journal of Educational Administration, No.(5),Vol.(40),

13- Femke,Geijsel and others (2003). Transform Leadership effects on teachers commitment and effort toward school reform, Journal of Educational Administration, No.(5), Vol.(41).

14- Wendy Keys, (et. Al)( 2003). Successful Leadership Of Schools In Urban And Challenging Contexts, national college for school leadership (ncsl), nottingham, p1 1

15- Office for standards in Education in England(2003). leadership and Managenemt managing the school workforce, Crown copyright, London, February, p3. 